\title{
Blood derivatives awaken in regenerative medicine strategies to modulate wound healing
}

Bárbara B. Mendes ${ }^{1,2}$, Manuel Gómez-Florit ${ }^{1,2}$, Pedro S. Babo ${ }^{1,2}$, Rui L. Reis ${ }^{1,2,3}$, Rui M. A. Domingues ${ }^{1,2}$, Manuela E. Gomes ${ }^{1,2,3}$

13B's Research Group - Biomaterials, Biodegradables and Biomimetics, Department of Polymer Engineering, University of Minho, Headquarters of the European Institute of Excellence on Tissue Engineering and Regenerative Medicine, Avepark - Parque de Ciência e Tecnologia, Zona Industrial da Gandra, 4805-017 Barco, Guimarães, Portugal. ${ }^{2}$ ICVS/3B's-PT Associated Laboratory, 4805-017 Braga/Guimarães, Portugal. ${ }^{3}$ The Discoveries Centre for Regenerative and Precision Medicine, Headquarters at University of Minho, Avepark, 4805-017 Barco, Guimarães, Portugal.

*Corresponding author; email: megomes@dep.uminho.pt

\begin{abstract}
Blood components play key roles in the modulation of the wound healing process and, together with the provisional fibrin matrix ability to selectively bind bioactive molecules and control its spatial-temporal presentation, define the complex microenvironment that characterize this biological process. As a biomimetic approach, the use of blood derivatives in regenerative strategies has awaken as a source of multiple therapeutic biomolecules. Nevertheless, and despite their clinical relevance, blood derivatives have been showing inconsistent therapeutic results due to several factors, including proper control over their delivery mechanisms. Herein, we highlight recent trends on the use
\end{abstract}


biomaterials to protect, sequester and deliver these pools of biomolecules in tissue engineering and regenerative medicine approaches. Particular emphasis is given to strategies that enable to control their spatiotemporal delivery and improve the selectivity of presentation profiles of the biomolecules derived from blood derivatives rich in platelets. Finally, we discussed possible directions for biomaterials design to potentiate the aimed regenerative effects of blood derivatives and achieve efficient therapies.

\section{Keywords}

Blood derivatives; biomaterials; wound healing; regenerative medicine; delivery; tissue engineering; platelet

\section{Table of contents}

1. Introduction

2. Mechanisms of wound healing and tissue regeneration

2.1. Inflammatory phase

2.2. Proliferative phase

2.3. Remodelling phase

3. Preparation and classification of blood derivatives

3.1. Platelet-poor blood derivatives

3.2. Platelet-rich blood derivatives

3.2.1. Platelet-rich plasma

3.2.2. Platelet lysate

3.2.3. Platelet-rich fibrin

3.3. Platelet-derived exosomes

4. Modulation of blood derivatives delivery 
4.1. Temporal profile

4.2. Spatial microenvironment

4.2.1. Impact on cell migration

4.2.2. Controlled architecture

4.3. Selection of specific bioactive molecules

4.4. Blood derivatives concentration

5. Concluding remarks and future directions

\section{Abbreviations}

Blood Derivatives - BD

Endothelial Growth Factor - EGF

Extracellular Matrix - ECM

Fibrin Glue - FG

Fibroblast Growth Factor - FGF

Growth Factors - GFs

Hepatocyte Growth Factor - HGF

Human Adipose-Derived Stem Cells - hASCs

Hyaluronic Acid - HA

Insulin Growth Factor - IGF

Interleukin - IL

Leukocyte-Rich Platelet-Rich Plasma -L-PRP

Matrix Metalloproteinases - MMP

Mesenchymal Stem Cells - MSCs

Plasma-Rich in Growth Factors - PRGF

Platelet Concentrate - PC 
Platelet Derived Growth Factor - PDGF

Platelet Gel - PG

Platelet Gel - PLG

Platelet Lysate - PL

Platelet-Derived Exosomes - PEx

Platelet-Poor Plasma - PPP

Platelet-Rich Fibrin - PRF

Platelet-Rich Plasma- PRP

Polycaprolactone - PCL

Red Blood Cells - RBCs

Three-Dimensional - 3D

Tissue Inhibitors of Metalloproteinases - TIMP

Transforming Growth Factor - TGF

Vascular Endothelial Growth Factor - VEGF

White Blood Cells - WBCs

\section{Introduction}

Wound healing following injury is a highly complex and dynamic process that can either lead to the formation of a scarred (repaired) or a regenerated tissue, depending on the multicellular organism, tissue and local signals $[1,2]$. Regenerative medicine holds the promise of promoting tissue regeneration in the body by therapeutically manipulating its natural ability to heal after injury or disease. As a concept, it applies various strategies for the management of diseases or healing processes, including the tissue engineering triad: biomaterials, cells, and signalling molecules [3-5]. These tools should control the swing between tissue regeneration and scar formation, promoting the regenerative 
pathway and avoiding the formation of fibrotic tissue [2]. In this context, blood components and their blood derivatives (BD) formulations can provide a wide range of biological elements (cells, growth factors (GFs), cytokines and scaffold-forming elements) that are essential in the regulation of wound healing mechanisms [6].

The use of different types of BD has shown positive clinical effects in several fields of regenerative medicine such as in the treatments of tendon injures and pathologies [7], cartilage disorders [8], as well as in periodontal [9] and soft tissue [10] wound healing. However, the systematic review of the literature shows conflicting results in the therapeutic outcomes, mainly due to the lack of standardization and poor characterization of formulations, which has led to an open debate on their real potential within the field $[11,12]$. Indeed, BD are a variable pool of cellular, sub-cellular and molecular components, making it difficult to draw strong conclusions on which formulation and therapeutic regime should be applied in a specific regenerative strategy. To overcome these limitations, the development of more controllable systems for the delivery of well characterized populations of biomolecules will certainly improve many clinical aspects on the use of $\mathrm{BD}$. In vivo, GFs are protected and stabilized via their binding to different extracellular matrix (ECM) components [13] that regulate their availability and signalling [14]. In a biomimetic strategy, researchers have combined BD with different biomaterials to modulate the delivery of bioactive molecules in order to guide the wound healing process.

In this review, we provide a theoretical and investigational framework to improve our understanding on the use of BD to modulate the wound healing process towards tissue regeneration as opposed to simple repair. Firstly, it is presented a brief overview of the fundamental molecular mechanisms of wound healing and tissue regeneration (section 2). Subsequently, in section 3 , it is provided a general introduction to the methods of 
preparation and classification of the different BD. In section 4, the recent strategies and findings on the modulation of BD delivery in a spatio-temporal, selective and concentration-dependent fashion are analysed in detail. In the final section (section 5) unresolved issues are critically discussed, providing possible directions for the progression of the field looking towards the future.

\section{Mechanisms of wound healing and tissue regeneration}

The natural reaction to injury is the immediate activation of the wound healing cascade, which primarily intends to restore tissue integrity and homeostasis. In healthy individuals, this process is relatively fast and effective, although it is often associated with scar formation, which can be unesthetic and impair the tissue function $[2,15]$. Research in the field of cutaneous wound healing [16] has made significant contributions to unveil the fundamental principles of wound repair and regeneration processes $[1,2]$. Nevertheless, wound healing stages and key principles are shared among different tissues $[2,17]$. For example, the events that follow a myocardial infarction are remarkably similar to that following a tendon or cartilage injury, a spinal-cord injury, a burn or a gunshot wound despite the different types of insult, the different organs affected, and the sterility of the wound $[2,18,19]$.

Wound healing can be divided in three overlapping phases: (i) haemostasis (secondsminutes) and inflammation (hours-days); (ii) proliferation or new tissue formation (daysweeks); and (iii) tissue remodelling (weeks-months-years, depending on wound type), (Fig. 1). This response can lead to the perfect regeneration of injured tissues and organs in some organisms, in contrast to simple repair of the damaged tissue. Although researchers have started to establish tissue-specific features of regeneration, the heterogeneity among different organisms and tissues is not well understood. Indeed, these 
complex processes are orchestrated by multiple cytokines, chemokines, and GFs secreted by multiple cell types, including platelets, neutrophils, macrophages, fibroblasts, endothelial and resident stem cells [2, 17].

\subsection{Inflammatory phase}

Immediately after tissue damage, the coagulation cascade is activated to prevent fluid and blood loss, leading to haemostasis. The extravasation of blood components triggers the formation of a platelet plug followed by a fibrin matrix, which provides a provisional scaffold for cell infiltration and proliferation [20,21]. At the same time, toll-like receptors at immune cells surface are activated by blood extravasation elements, ECM degradation products and bacteria. This causes the downstream activation of transcription factor nuclear factor kappa B, which induces the expression of proinflammatory mediators [18].

Platelets not only participate in the clot formation but also release large amounts of a wide variety of cytokines, chemokines, and GFs, extending their role beyond haemostasis to the participation in the innate immune system [22], inflammatory response [23], and tissue repair and regeneration [24-27].

Neutrophils are recruited to the wound in response to the activation of complement cascade, the degranulation of platelets, and bacterial products. These immune cells sterilize the wounds, phagocytizing bacteria and clearing cellular debris at the sites of tissue damage. However, its excessive activation may result in the killing of many otherwise-healthy host cells, a behaviour which is particularly prevalent in chronic wound situations [28]. In addition, neutrophils activate other cells through the release of inflammatory mediators, such as transforming growth factor- $\beta 1$ (TGF- $\beta 1$ ), interleukin (IL)-1 and -4 . As a key player in the initial inflammatory phase, TGF- $\beta 1$ induces the expression of proinflammatory genes that activates the recruitment of monocytes. At the 
injury site, monocytes differentiate into macrophages, which phagocytize dead cells and debris and coordinate tissue repair [28]. Macrophages also produce numerous cytokines (IL-1 and IL-6) and GFs (fibroblast growth factor (FGF), endothelial growth factor (EGF), TGF- $\beta 1$, and platelet derived growth factor (PDGF)) crucial for fibroblast recruitment and angiogenesis in the proliferative phase [29]. As the first inflammatory phase ends, pro-inflammatory macrophages (M1 macrophages), in response to IL-4, adopt an anti-inflammatory and reparative phenotype (M2 macrophages) to finalize the inflammation [30].

\subsection{Proliferative phase}

The proliferative phase consists on the formation of granulation tissue, ECM deposition, and angiogenesis. An interleukin in particular, IL-6, has important functions in the new tissue formation phase. IL-6 binding to its receptor activates the signal transducer and activator of transcription - Janus kinase pathway, which indirectly induces neutrophil and monocyte infiltration, fibroblasts migration and collagen deposition, and promotes angiogenesis by the induction of TGF- $\beta 1$, IL-1, vascular endothelial growth factor (VEGF), and hepatocyte growth factor (HGF) production [34]. In the case of skin, early migration of keratinocytes into the fibrin matrix leads to re-epithelialization. This process is aided by fibroblasts, which, attracted by TGF- $\beta 1$, among others, invade the fibrin network and progressively replace it for a collagen-rich connective tissue [25]. This provisional matrix or granulation tissue, invades the wound space and serves as a support for angiogenesis and later collagen remodelling [16]. Simultaneously, endothelial cells migrate into the wound attracted by VEGF and FGF-2 to form new blood vessels. Some fibroblasts undergo transformation into contractile myofibroblasts through TGF- $\beta 1$ pathway. These cells secrete copious amounts of collagen and express $\alpha$-smooth muscle 
actin, which allows the physical contraction of the wound $[35,36]$. However, excessive activation of myofibroblasts has been related to fibrotic diseases [37].

\subsection{Remodelling phase}

The final phase of wound repair involves a decrease in cellular content and is characterized by significant collagen remodelling. Most of the endothelial cells, macrophages, and myofibroblasts undergo apoptosis or exit the wound [2] while collagen

type III in the ECM is replaced by stronger collagen type I [17]. Remaining cells coordinate this process producing new collagen, matrix metalloproteinases (MMP) and their inhibitors, tissue inhibitors of metalloproteinases (TIMP), which work together to form collagen bundles and achieve the native tissue structure and strength [38]. In conclusion, a proper balance between degradation and synthesis of ECM is indispensable for normal wound healing. However, the repaired ECM of mature scar tissue differs considerably from that of unwounded tissue and is generally characterized by their comparatively lower biomechanical properties and functionality [45].

\subsection{Towards Tissue Regeneration}

In some eukaryotic organisms, the response to injury can completely recapitulate the original tissue architecture through regeneration. Though this process is poorly understood, researchers are beginning to uncover the individual components of tissue regeneration trough the study of animal models of regeneration and human tissues with self-regeneration ability [46].

A leading hypothesis is that immune cells have a prominent role in the swing between regeneration and repair [28]. Efficiently regenerating organisms, such as zebrafish, depend on macrophages to efficiently resolve inflammation and facilitate tissue 
remodelling and regrowth [31]. Furthermore, recent findings indicate that the sequential conversion of macrophages from M1 to M2 phenotype might have an important role in tissue regeneration [30]. For example, in skeletal muscle, the polarization of M2 macrophages promotes the release of IGF-1, that supports satellite cell growth and fusion to form new muscle fibres, and IL-10 and TGF- $\beta$, that suppress inflammation, stimulate angiogenesis and promote ECM remodelling, suggesting that modulation of macrophage polarization could improve muscle regeneration [47, 48]. Indeed, inflammation is necessary for the effective defence against pathogens and to set in motion the tissue repair mechanisms following injury, although excessive inflammation delays healing and results in increased scarring, compromising tissue regeneration [33].

As an example of the role of GFs in tissue regeneration, researchers showed that IGF and FGF signalling pathways are up-regulated during the fin regeneration in zebrafish. TGF- $\beta$ family members have as well an important role in the balance between wound repair and regeneration [36, 39]. While TGF- $\beta 1$ increases the expression of genes associated with ECM synthesis in fibroblasts, it also down-regulates MMP-1 [40] and induces the acquisition of the contractile myofibroblast phenotype to close the wound [35, 41], showing both anti-inflammatory and profibrotic activity. In addition, TGF- $\beta 1$ is also involved in the up-regulation of the angiogenic VEGF expression [42, 43]. On the other hand, while TGF- $\beta 2$ plays a similar role to TGF- $\beta 1$, the third isoform TGF- $\beta 3$, inhibits scarring and promotes better collagen organization in vivo [44]. In a clinical scenario, wounds that heal by scar formation, as opposed to tissue regeneration, have been shown to produce increased amounts of TGF- $\beta$ [2].

In addition, the liver is one of the few organs in the human body that regenerates efficiently after acute or even repetitive damage. Non-parenchymal cells in the liver, including macrophages and endothelial cells, are central in the coordination of the 
regenerative process. In particular, activation of VEGF receptor-2 in endothelial cells, stimulates the production of angiocrine factors and HGF, triggering hepatocyte proliferation and liver regeneration [49].

Mammals have retained much of the molecular machinery used by efficiently regenerating organisms, but their regenerative potential is only limited. In part, this seems to result from the rapid formation of fibrotic tissue, which probably conferred a survival advantage but prevented subsequent tissue regeneration $[2,46]$. In order to improve human health, GFs from BD could be a potential therapeutic strategy to transform fibrotic healing processes into regenerative ones.

I.

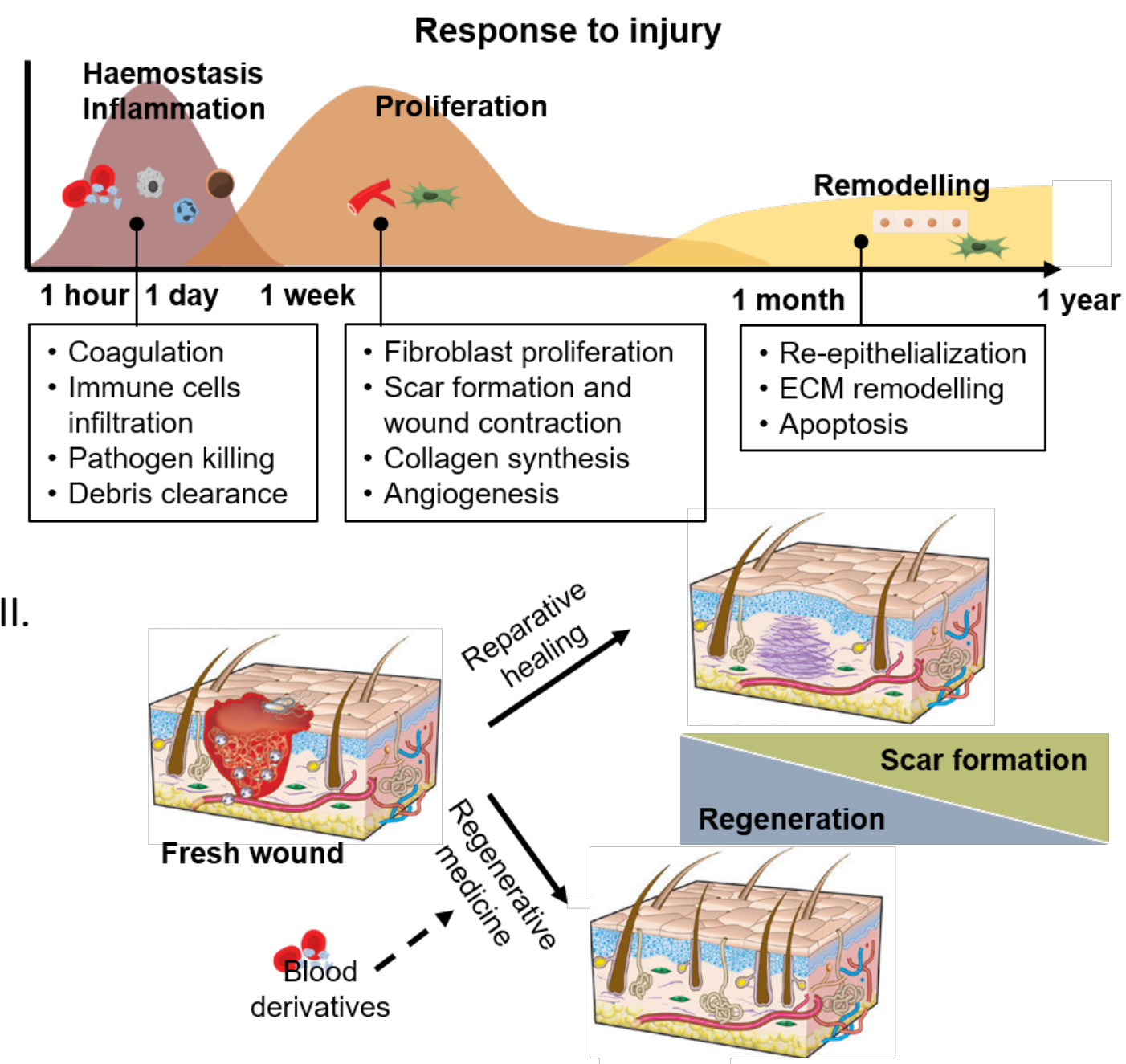


Figure 1. Overview of the classical wound healing phases vs regenerative medicine therapy approach. (I) Major wound healing events in a controlled spatial and precisely temporal response to injury. (II) The balance of these events plays an important role in the swing between tissue repair (scar formation) and tissue regeneration after injury. Considering BD content, rich in key biomolecules involved in the regulation wound healing mechanisms, its use will potentially alter the outcomes of this process. Adapted with permission from [2]. Copyright 2008, Nature Publishing Group.

\section{Preparation and classification of blood derivatives}

Blood is composed of different cellular, sub-cellular and molecular components that are involved in essential stages of wound healing [50-52] and regenerative processes [5355]. The separation of blood components results on the easy and fast production of different BD formulations, being classically produced by the double centrifugation technique (Fig. 2) [56]. Generally, it starts with a whole blood centrifugation, called the hard centrifugation, in order to separate the blood into three phases: 1) a lower layer rich in red blood cells (RBCs); 2) an interface layer (buffy coat) rich in white blood cells (WBCs) and platelets; and 3) an upper layer corresponding to the blood plasma with platelets in suspension (Fig. 2-IA). Alternatively, if an anticlotting agent (e.g. heparin or citrate) was previously added, it can be collected (alone or in combination with the buffy coat) and submitted to a further centrifugation step, called the soft spin (Fig. 2-IC), to produce a fraction poor in platelets (platelet-poor plasma (PPP)) and a fraction rich in platelets (platelet concentrate (PC) or platelet rich plasma (PRP)) [56]. Table 1 summarizes the most relevant biomolecules found in BD with therapeutic interest along with their main cellular sources. These soluble factors regulate important cell functions such as chemotaxis, proliferation and differentiation [53-55]. Moreover, some BD are 
rich in structural proteins, such as fibrinogen [57] (or its polymerized product fibrin), and fibronectin [58], which may act as a provisional matrix for cell adhesion and migration [52]. Fibrinogen of platelet concentrates is commonly activated by calcium and exoor/and endogenous thrombin producing a stable fibrin matrix [59]. Both the fibrinogen content and activation strategy have a marked impact over the physical properties of the resulting fibrin matrix, namely on the fibre diameter and network density that will define the in vitro and in vivo stability of the clot, its mechanical properties and its ability to sequester the bioactive molecules released by the platelets [60]. Additionally, BD have also been reported to exhibit antimicrobial properties [61-64], attributed to the presence of $\beta$-lysin [65], neutrophil activating protein-2 [66, 67], CXC chemokine ligand-4 [68, 69], or complement proteins [64] which can contribute for maintaining the prophylaxis of the wound site.

The lack of standardization in origin (auto-, allo- or xenogenous) and preparation methods (donors number, anticoagulant agent, activation method) of BD generally leads to marked differences in the composition of the formulations, particularly in terms of cellularity mainly characterized by the platelet concentration and the presence/absence and concentrations of WBCs and RBCs [60, 70-72]. At the end, the presence, concentration, protection, release and diffusion of bioactive molecules of interest (Table 2) from BD will be affected by all these parameters and therefore, their preparation is of utmost importance as the first step to control and ultimately achieve the aimed therapeutic effect.

\subsection{Platelet-poor blood derivatives}

The PPP is a liquid solution of blood plasma with very low cellular content. It is obtained, as above described, from whole blood supplemented with an anti-clotting agent, 
after cycles of centrifugation The PPP is generally used in clinics mainly as a wound patch termed as fibrin glue (FG), after induction of the coagulation cascade (Fig. 2 -ID) [56]. It has been shown to be haemostatic and to improve the wound healing [73]. FG is produced by polymerizing the fibrinogen contained in PPP with thrombin and calcium [73] or other coagulation activator. Given the low platelet content, FG is almost depleted of GFs of platelet origin (summarized in table 2) [74, 75], although some GFs, such as insulin growth factor-1 (IGF-1) and HGF, can be found in FG [74]. Despite the lack of GFs of platelet origin, FG was shown to be more effective than activated PRP or PRF for the preservation of sockets with buccal dehiscence [75]. The authors hypothesized that the absence of anti-morphogenic factors of platelet origin, such as the PDGF [76], and the higher fibrin content (Table 2) [75] would enhance the osteoconductive and/or osteoinductive properties of FG over PRP and PRF.

\subsection{Platelet-rich blood derivatives}

As mentioned before, the fraction rich in platelets is termed as platelet-rich BD. During the last two decades, several platelet-rich BD have been developed using the same generic name "PRP". Further than the nomenclature controversy, the ambiguous outcomes reported for the in vitro and clinical application of these different "PRPs" have early unleashed the discussion on the need of an adequate classification method $[56,60$, 77].

\subsubsection{Platelet-rich plasma}

PRP is generally defined as a volume of autologous plasma with a platelet concentration above blood baseline (between $1.5 \times 10^{5} / \mu \mathrm{L}$ and $3.5 \times 10^{5} / \mu \mathrm{L}$ ) [56]. PRP can be used directly as a liquid formulation or activated through different methods, including 
the addition of thrombin [78], thromboplastin [79], calcium salts [78-81] or collagen [82] promoting the formation of a fibrin network containing activated platelets, termed platelet gel (PG) (Fig. 2 -IE) [83]. The supernatant, a solution of GFs released upon platelets activation in blood plasma, herein termed plasma rich in growth factors (PRGF), has also been explored [55, 62]. The activation of platelets contained in PRP induce the degranulation of $\alpha$-granules and the release of several cytokines and growth factors, including TGF- $\beta$ - 1 and -2, PDGF-A and -B, EGF, VEGF, and FGF $[55,74,84,85]$ (Table 1). However, their relative concentration varies considerably between batches and activation products.

Four major factors were identified to influence the composition of the PRP and PRP products: 1) the platelet content; 2) the presence of other cells of blood origin, namely WBCs; 3) platelet activation protocol; and 4) donor-to-donor variability. The first three factors are the basis for most of the PRP classification systems, namely those proposed by Ehrenfest [77] and DeLong [86]. Nevertheless, among these factors, platelet content will have a major effect in the concentration of GFs of platelet origin [87], and thus in the possible therapeutic outcomes. Therefore, Marx and colleagues [56] proposed that, for clinical applications, PRP should be defined as a concentration of platelets with a consistent therapeutic efficacy, while all the suspensions of platelets in plasma above the blood baseline could be generally termed PC. Since the concentration of platelets that has been proven to have therapeutic efficacy for bone healing is around $1 \times 10^{6} / \mu \mathrm{L}[56,88]$, this has been proposed as the platelet content that defines a platelet suspension as PRP. However, in literature, some works using products termed "PRP" either overlook the platelet concentration [89] or use PC with different platelets concentration [90]. Commercially available kits (e.g. PRGF®-Endoret ${ }^{\circledR}, \operatorname{PCCS} \AA$, Harvest ${ }^{\circledR}$ SmartPrep ${ }^{\circledR}$ ) have aimed at establishing good manufacturing practice protocols for PRP derivatives 
production, particularly to reduce the protocol-related variability. Nevertheless, different PRP preparation kits still yield significantly different platelets concentration [87, 90]. For example, the preparation of PRP from a single donor using PCCS ${ }^{\circ}$ or PRGF® kits yielded differences in leukocytes, platelets and GFs content. PCCS ${ }^{\circledR}$ collects $1,641,800$ $\pm 426,820$ platelets $/ \mu \mathrm{L}$, which results in a significantly higher content of TGF- $\beta 1$ and PDGF-AB, in comparison with PRGF ${ }^{\circ}$ that collects $513,630 \pm 139,470$ platelets $/ \mu \mathrm{L}[90]$. These results might be explained by the collection protocol, since in the PRGF® kit the buffy coat (contains leukocytes and platelets) is not used and a second centrifugation (hard spin for platelet concentration) is not performed. Therefore, differences in the PRP preparation method might explain the conflicting therapeutic results [11], which emphasizes the need to standardize the platelet concentration and/or the use of a pool of donors to obtain reliable therapeutic effects.

The leukocytes, mainly neutrophils and macrophages, are usually isolated from the whole blood together with platelets during PRP preparation [91]. These cells can contribute with cytokines, GFs and proteases involved in the modulation of inflammation and clot remodelling [92-94] (Table 1). Based on the potential effect of the WBCs content, Ehrenfest and co-workers have defended the necessity to classify PRP based on their leukocytes content: leukocyte-rich PRP (L-PRP) and the leukocyte-poor PRP or “pure"-PRP (P-PRP) (and, generalizing, all the platelet-rich BD and PRP activated products) $[60,77]$ (Figure 2 -II). Studies comparing the releasate of leukocyte-rich PG and leukocyte-poor PG clots, reported no differences in the released concentration of several relevant GFs, namely PDGF, VEGF, and TGF- $\beta 1[95,96]$ (Table 2). On the other hand, due to their higher WBCs contents, leukocyte-rich PG released higher concentrations of proinflamatory cytokines, namely IL-1 $\beta[95,96]$ and TNF $\alpha[96]$. 
Although results tend to suggest that presence of WBCs in BD might foster undesired proinflammatory effects, systematic reviews have shown inconclusive results in the use of L-PRP and P-PRP [12]. For example, L-PRP might be less suitable for acute tendon conditions because of its catabolic and inflammatory features. On the other hand, P-PRP could induce the formation of excessive scar tissue due to its potent anabolic action [97]. This exemplifies the current gaps of knowledge on the optimal BD formulations to be applied in the treatment of inflammatory diseases or in regenerative strategies. Furthermore, there is a clear difference between the PG clot and the PRGF liquid solution formulates, mainly because of the platelet activation protocol. Besides the fibrin content, differences can be observed in the concentration of some growth factors [74] (Table 2). For instance, while the concentration of TGF- $\beta 1$ is pretty similar between PG and PRGF obtained by PRP activation with either calcium or thrombin, the concentration of e.g. EGF is consistently higher in PRGF than in PG regardless the activation method [74], as a result of their different affinities for the fibrin matrix [98]. The activation method has also been shown to influence the structural characteristics of PRP activated products and consequently the composition of their releasates. PG clots formed using type I collagen exhibited far less retraction than those formed with bovine thrombin [99]. Moreover, while both PGs activation protocols resulted in similar PDGF and VEGF release profiles between 1 and 10 days, thrombin activation resulted in a comparatively higher release of TGF- $\beta 1$ during the first 5 days [99].

Finally, there is a considerable variability between the proteins released from different platelet donors [74, 100], which should be a major concern when PRP is envisioned for autologous therapies. For instance, Kalén and co-workers observed a remarkably high variability between donors on the release of bone morphogenetic proteins (BMPs)-2, -4, -6, and -7 from P-PRP [100]. In fact, platelets of only one of thirty 
donors released BMP-2 at physiologic $\mathrm{pH}$ [100]. This variability is of paramount relevance for GFs with a major function in the regeneration of the targeted tissue such as, in this particular case, the activation of BMPs signalling pathway for osteogenic differentiation $[101,102]$. In order to mitigate this problem, in last few years the use of PRP pools from different donors in alternative to single-donor PRP has been proposed, as they yield PRP preparations with more consistent GFs and cytokine contents than single-donor batches [74].

\subsubsection{Platelet lysate}

Platelet lysate (PL) is obtained by freeze/thaw cycles $[84,85]$ or by ultrasounds [103] to disrupt the platelets contained in PC batches, either produced by centrifugation cycles [85] or by apheresis [84, 85]. PL is a liquid solution of biomolecules, and although its platelet content release is obtained by cellular disruption instead of $\alpha$-granules degranulation, it contains most of the GFs commonly found in other platelet-rich BD $[84,85]$. Nevertheless, the concentration of some GFs, namely PDGF, is significantly lower in PL than in PRGF [104] (Table 2) emphasizing the relevance of BD production method on their bioactive molecules composition.

PL offer several advantages for therapeutic applications: 1) the clot and platelet debris are removed during PL processing, therefore, the PL is a solution that hardly forms spontaneously a gel or retracts; 2) the freeze/thaw cycles are easy to standardize and do not require the addition of any clot activator to release the platelet factors; 3) the concentration of the growth factors and cytokines is highly reproducible between batches, which can contribute for more predictable outcomes; 4) it can be frozen and stored to be readily available for further use [84]. 
For TE applications, PL can be processed into a PL gel (PLG) using thrombin [103], or loaded into carriers for the sustained release of PL GFs [105, 106]. These constructs incorporating PL have shown potential to induce neovascularization [103], osteogenesis $[105,106]$ and to enhance periodontal re-attachment [107]. PL has also been proposed as a prevailing alternative to foetal bovine serum supplement for culture of several human cell types $[84,108]$.

\subsubsection{Platelet-rich fibrin}

PRF is a second generation platelet-rich BD proposed by Choukroun [109] as an easier to prepare and completely autologous alternative to PRP. Dohan classified PRF as an autologous leukocyte-PRF matrix [110] termed L-PRP by some authors. Since PRF is produced by the spontaneous coagulation of the upper layers obtained after the hard spin of whole blood (Fig. 2 -IB), in addition to platelets, it also incorporates all the cells that remain entrapped within the fibrin clot, namely RBCs and WBCs [109-111]. In fact, contrarily to other platelet-rich BD which are produced from homogeneous suspensions of platelets, PRF clots have a cell gradient starting from the bottom, which is highly rich in RBCs, WBCs and platelets, to the top, which is almost depleted from cells [111]. Therefore, the WBCs or RBCs content of PRF can be easily reduced by cutting the bottom end of the clot $[112,113]$. PRF contains several of the GF and biomolecules with therapeutic interest found in other platelet-rich BD $[111,113]$ (Table 2). However, the GFs distribution throughout the PRF clot follows the cellular gradient, being more concentrated in the lower portion than in the upper portion of the clot [111, $113]$. 


\subsection{Platelet-derived exosomes}

The platelet-derived exosomes (PEx) are extracellular vesicles with sub-micrometre diameter (40-100 $\mathrm{nm})$ characterized for expressing the specific markers CD9, CD63, CD81 and the marker of platelet origin CD41 [114-116]. Blood circulating exosomes, from which the platelet-derived should represent about 25\% [117], are known to be involved in vascular remodelling [118]. In fact, PEx mediate platelet atherogenic interactions with endothelial cells and monocytes [119].

PEx are true effectors within the overall platelet function and have been shown to be highly modulated by the environmental conditions. They carry several of the most important GFs of platelet origin, namely PDGF-BB, TGF- $\beta 1$, VEGF, and FGF-2 [116]. Moreover, PEx incorporate mRNA [114] and might be responsible for the paracrine modulation of ICAM-1 gene expression in endothelial cells mediated by miRNAs [119, 120] (Table 1). Despite being produced constitutively, their number and cargo depend on the platelets' activation process [115]. Aantonen and co-workers demonstrated that the activation of platelets with calcium produced higher amount of exosomes than the thrombin combined with collagen or lipopolysaccharides activation [115].

For biomedical applications, PEx can be easily isolated from PL [114] or from activated PRP [116] by ultracentrifugation and ultrafiltration. Recent studies demonstrated the internalization of PEx by mesenchymal stem cells (MSCs) and its dosedependent positive effect on cell migration, and osteogenic differentiation [114]. However, before implement PEx as a regenerative medicine approach, future research need to explore the content of these vesicles and understand their fundamental role on tissue development. 
Table 1. Summary of cellular, sub-cellular and molecular components of blood derivatives relevant for wound healing.

\begin{tabular}{llll}
\hline & \multicolumn{1}{c}{ Main components } & \multicolumn{1}{c}{ Key functions } & Ref. \\
\hline Plasma & & & \\
Adhesive & Albumin, globulins, & Haemostasis, clot maturation, & \\
proteins & fibrinogen, complement & cell adhesion, activation of the & \\
& proteins, and clotting factors & immune response & \\
& Chloride, sodium, and & & \\
Electrolytes & calcium & Haemostasis & \\
& & & \\
Growth & IGF-1, HGF, FGF-2, GH & Regulation of cell proliferation & \\
factors & & &
\end{tabular}

\section{Platelets}

\section{Alpha granules}

$\begin{array}{lll}\begin{array}{ll}\text { Adhesive } \\ \text { proteins }\end{array} & \begin{array}{l}\text { Fibronectin, vitronectin, } \\ \text { fibrinogen, vWF, P-selectin }\end{array} & \begin{array}{l}\text { Platelet aggregation, platelet- } \\ \text { endothelial cell interaction, } \\ \text { thrombus formation }\end{array} \\ \text { Clotting } & \text { Factors V, XI, and XIII } & \text { Haemostasis, thrombus } \\ \text { factors } & & \text { formation } \\ \text { Growth } & \text { PDGF, TGF- } \beta \text {, VEGF, FGF- } & \text { Regulation of cell } \\ \text { factors } & \text { 2, EGF, and BMPs } & \text { proliferation, differentiation, } \\ & & \text { and angiogenesis } \\ \text { Cytokines / } & \text { IL4, IL8, TFN } 2, \text { CXCL4, } & \text { Chemotaxis, inflammatory } \\ \text { Chemokines } & \text { CXCL7, CCL2, CCL3, and } & \text { response modulation, } \\ & \text { CCL5 } & \text { antimicrobial activity } \\ \text { Complement } & \text { Complement C3 and } & \\ \text { proteins } & \text { complement C4 precursor } & \text { Antimicrobial activity }\end{array}$


$\alpha 2$-macroglobulin, $\alpha 2-$

Others

antiplasmin, microbicidal

proteins

ADP, ATP, calcium,

Dense

granules

Lysosomes Proteases, hydrolases

Adhesion proteins (P-

selectin), genetic material

(mRNA, miRNA), growth

Exosomes

factors (VEGF, PDGF, TGF-

$\beta 1$, FGF-2) chemokines

(CXCL4, CXCL7)
Protease inhibitors,

antimicrobial activity

Platelet activation,

vasoconstriction

Matrix degradation,

antimicrobial activity

Cell adhesion, paracrine

communication, angiogenesis,

regulation of cell fate,

modulation of inflammatory

response

\section{Leukocytes}

Cytokines (IL-1, IL-4, IL-6,

Neutrophils

and TNF- $\alpha$ ), growth factors

Phagocytosis, chemotaxis, and

matrix remodelling

(TGF- $\beta 1)$, and proteases

Cytokines (IL-6, IL-1 $\beta$, IL-8,

Monocytes/

IL-10, TNF- $\alpha$, GM-CSF), Phagocytosis, modulation of

Macrophages

growth factors (TGF- $\beta 1, \quad$ inflammatory response, and

FGF, EGF, PDGF),

matrix remodelling

proteases

\section{Erythrocytes}

ATP, nitric oxide, $\quad$ Vasodilatation, antimicrobial

haemoglobin, free radicals

activity 
Abbreviations: bone morphogenic proteins (BMPs); C-C motif chemokine ligand (CCL); CXC chemokine ligand (CXCL); endothelial growth factor (EGF); fibroblast growth factor-2 (FGF-2); granulocyte-macrophage colony-stimulating factor (GM-CSF); growth hormone $(\mathrm{GH})$; hepatocyte growth factor (HGF); insulin growth factor-1 (IGF-1); interleukin (IL); platelet derived growth factor (PDGF); tumour necrosis factor alpha (TNF $\alpha)$; transforming growth factor- $\beta$ (TGF- $\beta$ ); vascular endothelial growth factor (VEGF); von Willebrand factor (vWF). 

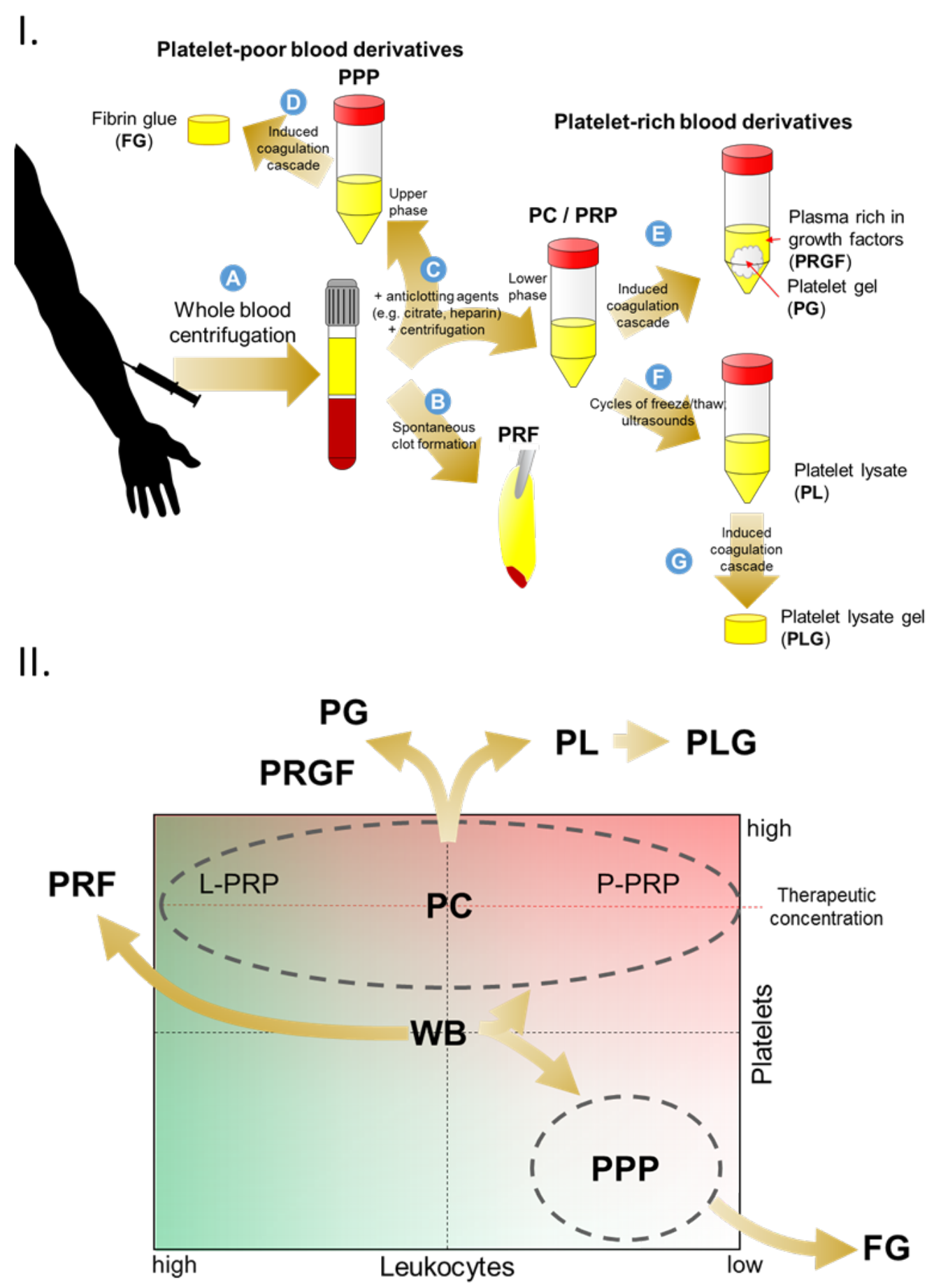

Figure 2. Blood derivatives production and content differences. I. Conventional (manual) method for the production of different BD. A) The centrifugation of whole blood (WB) induces the separation of the blood components into 3 layers. B) The upper layer, a yellowish solution composed mainly of plasma and platelets, coagulates spontaneously if no anticlotting agent is previously added to the whole blood, originating a fibrin mesh 
rich in platelets and leucocytes termed platelet rich fibrin (PRF). C) The whole blood supplementation with anticlotting agents allows the upper layer to remain liquid. It can be therefore collected (together or not with the buffy coat) and further centrifuged to produce platelet-poor plasma (PPP) or platelet concentrate (PC), also called platelet-rich plasma (PRP). D) The induction of PPP clotting originates fibrin glue (FG). Likewise, E) the induction of PC or PRP clotting originates the platelet gel (PG), and plasma rich in growth factors (PRGF). Alternatively, F) the platelets of PC/PRP can be disrupted by freeze/thaw cycles or by ultrasounds, originating a solution of platelet lysate (PL), which can produce platelet lysate gel (PLG) by fibrinogenesis activation. II. Diagram depicting the relative cellular content of each blood derivative and their precursors, compared to the physiologic levels (---) in whole blood, throughout the preparation and activation processes.

Table 2. Qualitative comparison of the most relevant GFs and fibrin present in BD relative to the physiological blood serum levels..

\begin{tabular}{|c|c|c|c|c|c|c|c|}
\hline \multirow{2}{*}{ Growth factors } & \multirow{2}{*}{$\begin{array}{l}\text { Blood serum } \\
\text { levels }(\mathrm{ng} / \mathrm{mL})\end{array}$} & \multirow{2}{*}{$\begin{array}{l}\begin{array}{l}\text { Platelet- } \\
\text { poor BD }\end{array} \\
\text { PPP }\end{array}$} & \multicolumn{3}{|c|}{ Platelet-rich BD } & \multirow{2}{*}{ PEx } & Refs \\
\hline & & & PRGF & PRF & PL & & \multirow{8}{*}{$\begin{array}{l}{[57,64,} \\
72-74,92, \\
94,104, \\
116,130- \\
139]\end{array}$} \\
\hline PDGF-BB & $3.84 \pm 2.47$ & - & ++ & + & + & +++ & \\
\hline VEGF & $0.17 \pm 0.06$ & - & + & + & + & + & \\
\hline TGF- $\beta 1$ & $25.42 \pm 5.4$ & - & + & + & ++ & +++ & \\
\hline FGF-2 & $0.0055 \pm 0.0043$ & - & +++ & +++ & +++ & +++ & \\
\hline IGF-1 & $74.37 \pm 47.63$ & + & + & + & + & $\mathrm{u}$ & \\
\hline EGF & $0.07 \pm 0.06$ & - & +++ & $\mathrm{u}$ & +++ & $\mathrm{u}$ & \\
\hline $\begin{array}{c}\text { Fibrin/fibrinogen } \\
\text { (plasma) }\end{array}$ & $2.4 \pm 1.4 \times 10^{6}$ & + & N/A & ++ & - & $\mathrm{N} / \mathrm{A}$ & \\
\hline
\end{tabular}


Abbreviation: "-" $\leq 1$-fold; "+" > 1-fold; "++" $\geq$ 5-fold; "+++" $\geq 10$-fold "N/A" nonapplicable; "u” unknown. 


\section{Modulation of blood derivatives delivery}

Along the last few decades, the use of BD formulations in clinical applications has relied on 1) direct injection of a liquid form and activation by tissue collagen and thromboplastin, which form a gel in situ [140]; or 2) induction of the coagulation cascade prior to administration to produce a fibrin matrix-based scaffold [141]. Despite the numerous positive reports on the use of $\mathrm{BD}$ as biomaterial free strategies in tissue regeneration and decades of research on this field, some inconsistent and sometimes contradictory results are still frequently found [11]. The clear cause-effect relationship of these results is difficult to establish due to the complexity and also conflicting presence of multiple biomolecules in these formulations, showing that new strategies are necessary to overcome these limitations.

As previously described, the normal wound healing process involves the formation of a fibrin network that acts as a sequestering matrix for the blood cellular components and its secretome, while providing a temporary scaffold that will support tissue repair. This matrix protects the bioactive soluble cargo from fast clearance and proteolytic degradation, thus, controlling its release profile, which will ultimately dictate the overall wound biological response. In a biomimetic regenerative medicine approach, the combination of $\mathrm{BD}$ with biomaterial platforms might enable the control of the spatiotemporal and selective delivery of signalling biomolecules [2]. This strategy would potentiate their therapeutic effect and enhance tissue healing, shifting the normal reparative response, generally leading to non-functional scar tissue formation, towards a regenerative outcome (Fig. 1). This concept is being developed using a wide range of natural and synthetic polymers, inorganic materials, or their blends combined with BD. Several strategies have been explored to tune the biomaterial/BD interactions ranging from BD covalent (chemical or enzymatic crosslinking) and non-covalent immobilization 
(affinity-based systems, including electrostatic/ionic interactions, hydrogen bonding and van der Walls forces, mimicking the ECM binding mechanisms) to simple physical entrapment $[14,142]$. Therefore, each specific combination of biomaterials and BD will show unique biomolecular binding affinities and release profiles, suggesting that numerous engineering possibilities are open to be explored within this field [143-148]. In addition to the biological cues provided by BD, biomaterial intrinsic properties (physical, mechanical and chemical cues) can also add an additional level of control over cellular behaviour (recently defined as Materiobiology) [149], and therefore synergistically potentiate the regenerative process.

In this section, we survey the application of specific combinations of biomaterials with $\mathrm{BD}$ that are intended to deliver bioactive molecules in mechanisms mimicking the cascade of natural signalling events guiding to wound healing process. These include strategies to control the selective, temporal, spatial, and concentration-dependent release profiles of BD biomolecules in order to foster tissue/organ regeneration (Fig. 3 and Table 3). It should be noted that strategies comprising only components of the $\mathrm{BD}$, are not under the scope of this review. For further information on the topic the readers are referred to other recent and comprehensive reviews [6, 108, 150-152].

\subsection{Temporal profile}

The time frame in which a beneficial therapeutic effect can be achieved with bioactive molecules is limited. For example, soluble GFs have short in vivo half-lives (in the order of minutes), degrading or being deactivated via several distinct pathways, including denaturation, oxidation or proteolysis, which restricts their dose and temporal bioactivity $[144,147]$. On the other hand, the extended presence of GFs within a local microenvironment can lead to abnormal tissue growth. Therefore, the modulation of the 
temporal delivery profile of bioactive molecules from BD is crucial to control their therapeutic efficiency during the wound healing phases.

Nano - and micro-particles based carriers have been widely used in drug delivery and tissue engineering approaches in order to protect the cargo and control its release to the cells' extracellular fluid or directly within the cells [153-155]. These type of carriers have also been explored for the controlled deliver of BD. For example, PL was adsorbed on the surface of positively charged chitosan/chondroitin sulphate nanoparticles prepared by polyelectrolyte complexation of the two oppositely-charged polysaccharides [105]. Chitosan, a bioresorbable and positively charged natural polymer, has been traditionally applied to develop different carrier systems and has shown to be able to regulate the release of bioactive agents, including GFs $[156,157]$. On the other hand, chondroitin sulphate is an anionic sulphated glycosaminoglycan that act as a stabilizer and also interacts with different biomolecules in the ECM [158]. Exploring their polyelectrolyte nature and biological function, chitosan/chondroitin sulphate nanoparticles allowed to modulate the temporal release profile of electrostatically adsorbed PL proteins which extend up to 1 week. As the nanoparticles undergo fast cellular internalization (in part due to their positive surface charge), this system might be applied as an intracellular delivery vehicle of PL bioactive agents [105]. Interestingly, besides their application as carriers, these nanoparticles were also used to produce three-dimensional (3D) structures. In a bottom-up strategy, chitosan/chondroitin sulphate nanoparticles loaded with PL spontaneously self-assembled (at high concentrations) into stable 3D structures, simultaneously entrapping human adipose-derived stem cells (hASCs) [159]. The system showed an initial burst release of PDGF-BB and TGF- $\beta 1$ after one day $(92 \%$ and $80 \%$ of their initial amount). This release pattern was correlated with the higher hASCs proliferation observed at early time points, compared to cultures on unload particles and 
in form of cell pellets. The PL function was not only to be a source of bioactive molecules, but also acted on the physical stabilization of the system, creating a more appropriate 3D environment for hASCs survival and ECM synthesis. In contrast, the incorporation of the aforementioned nanoparticles within scaffolds (foams processed by supercritical $\mathrm{CO}_{2}$ ) of poly(D,L-lactic acid) slowed the initial burst release of PDGF-BB, TGF- $\beta 1$ and VEGF to $50 \%$ after one day, prolonging its sustained delivery up to 28 days [160]. The 3D hybrid scaffolds promoted the earlier osteogenic differentiation of hASCs compared to the controls, demonstrating the potential of the proposed combinatory approach for bone regeneration. Similarly, PL adsorbed on microparticles of hyaluronic acid (HA), a negatively charged non-sulphated glycosaminoglycan, were incorporated in calcium phosphate cements pastes for bone regeneration applications [106]. The use of HA microparticles as carrier clearly maximized the amount of PL that is possible to load into the composites cements without affecting their setting properties and also had a significant impact on the protein release profiles. Compared to direct mixing with the cements, the preloading of PL into HA microparticles resulted in higher total protein but lower TGF- $\beta$ release from the composite. Interestingly, the osteogenic potential of the system was enhanced when PL was directly mixed with the cement formulation, which might be correlated with their higher release rates of TGF- $\beta$. These studies are representative of how biomaterial engineering strategies may explore the electrostatic interactions between proteins and polyelectrolyte polymeric matrices to modulate the release kinetics of $\mathrm{BD}$ molecules. For example, albumin, which is the main soluble protein of PL [161] and has an acidic isoelectric point (at pH 4.7), is expected to be nonspecifically adsorbed and easily washed out from negatively charged polymers, such as HA [162]. On the other hand, since most of the GFs present in PL with therapeutic interest have basic isoelectric point (e.g. TGF- $\beta$ at $\mathrm{pH}$ 8.90; PDGF-B at $\mathrm{pH}$ 9.39), they can 
electrostatically bind to negatively charged polymers, such as sulphated glycosaminoglycan, as it naturally occurs in the native ECM [163].

The different processing techniques applied to incorporate BD into scaffolding biomaterials has also shown to significantly impact the temporal release profile of GFs. For example, in chitosan based scaffolds produced by freeze-drying, adding PRP to chitosan gel before the freeze-drying process improved the scaffold structural properties and provided a more controlled release of PDGF-BB, IGF-1 and TGF- $\beta 1$ for 20 days, as compared to PRP post-embedding in the scaffold [164]. On the other hand, no major differences were observed when PL was loaded before or after freeze-drying in sponge scaffolds made of chitosan glutamate, sericin and glycine, both showing similar positive outcomes in an ex vivo human skin biopsy model [165].

During the last few decades, hydrogels became one of the most popular types of biomaterials in TERM due to their inherent similarities (structural, chemical and compositional) with the native ECM of soft tissues [166, 167]. A representative example of this strategy is the recently proposed photoinducible imine crosslinking hydrogel glue system based on the imine crosslinking of o-nitrobenzyl alcohol modified-HA (which generates aldehyde groups upon light irradiation) with amine groups of the proteins present on autologous PRP and also with the tissue surface [168]. The proposed system allowed the sustained release of PDGF, TGF- $\beta$ and FGF over 14 days, alleviating the burst release of GFs (2 days) observed on PG (thrombin activated). These differences might be explained by the fact that platelets in the hydrogel were not disrupted while platelets in PG were activated with thrombin, which leads to fast platelet content secretion [169], but also by the positive contribution of the modified-HA matrix on the sequestration of platelet-released GFs. Considering that platelets secrete $80-100 \%$ of their content during the first hour after activation [169], these results tend to suggest that the 
incorporation of inactivated platelets (PRP) in a hydrogel matrix might prolong the sustained release of bioactive molecules, improving the overall wound healing in the long-term. Interestingly, the aforementioned HA-PRP hydrogel also enhanced chondrocyte and stem cell long-term proliferation and migration, resulting as well in stronger tissue adhesiveness and integration in vivo than PG formulation [168]. In a different application, freeze-dried chitosan solubilized in L-PRP was used to form stable, non-retracting and homogenous injectable implants that coagulate in situ [170]. In a subcutaneous animal model, these chitosan-PRP implants remained physically stable for at least 2 weeks, while PRP controls lost up to $80 \%$ of their original mass and were quickly degraded in one day. Moreover, the chitosan-PRP formulations induced cell recruitment (macrophages) and angiogenesis after 14 days in vivo, suggesting a strong potential for their application in meniscus, cartilage or rotator cuff repair.

The type of $\mathrm{BD}$ and their nature (gel or soluble factors) in combination with biomaterials might be an interesting option to modulate the GFs temporal release profile and sequestering pattern. For example, PG and PRGF (both calcium activated) were incorporated into gelatin-nanohydroxyapatite nanofibrous composite scaffolds as a coating or lyophilized within the scaffold nanofibers, respectively [171]. Although both formulations could release GFs (VEGF and PDGF) during 4 weeks, scaffolds incorporating PRGF within the polymer matrix exhibited a steady release profile for both VEGF and PDGF whereas PG coated scaffolds exhibited an initial burst release which gradually declined over time, demonstrating that BD loading method in the biomaterials has a pronounced impact over the release patterns of their bioactive molecules. Overall, these results have been showing that by rationally selecting the biomaterials and processing technique it is possible to modulate the delivery profiles of biomolecules from $\mathrm{BD}$ in a time frame that can spam from days (burst release) to weeks (sustained release). 
Nonetheless, these approaches still present limitations to reproduce the sequential presentation and time-dependent release of GFs involved in specific phases of wound healing. For example, TGF- $\beta 1$ promotes cell recruitment during the inflammatory phase, however its presence in latter stages induces scar formation. Besides controlling this transient release, it is as well important to control the delivery of multiple GFs to allow tissue regeneration. Namely, in order to promote angiogenesis at the proliferative phase, VEGF and FGF-2 are required to form immature blood vessels. To enable this biochemical signalling at the required time, the polymer composition, type of crosslinker and crosslinking density can be manipulated to control their swelling behaviour and degradation rate. Using an implant composed of PLGA microspheres loaded with BMP2 embedded in a poly(propylene) scaffold, which was surrounded by a gelatin hydrogel loaded with VEGF, a sequential delivery of angiogenic factors, within the first three days, and osteogenic factors, in later stages, was achieved, which resulted in ectopic bone formation [172]. Other biomaterials that could be explored in the future are stimuli responsive materials ( $\mathrm{pH}$, temperature or magnetic fields) that might be used to trigger the on-demand delivery of specific biomolecules at desired healing phases [173]. At the end, these properties will engineer the temporal release of bioactive molecules to fit in the chronologic events of the wound healing process and ultimately enhance the regenerative response [142].

\subsection{Spatial microenvironment}

The spatial microenvironment of a healing wound is affected by ECM remodelling, autocrine and paracrine cell signalling, and cells fate, including proliferation, differentiation, migration and apoptosis [142]. Along with the available tools to engineer the intrinsic physical and chemical properties of biomaterials, the precise spatial control 
over bioactive molecules delivery will more closely recapitulate the heterogeneity and physical/chemical gradients occurring in native ECM, and therefore, boost the regenerative process. BD have been combined with different scaffold fabrication strategies in order to promote cell migration over and to the scaffold, or to produce well defined 3D architecture that can better replicate the several length scales of the complex architecture of native tissues by the introduction of hierarchical structures in the developed composite biomaterials. Representative examples of these strategies are highlighted in the next paragraphs.

\subsubsection{Impact on cell migration}

Nano- microfiber non-woven scaffolds show unique architectural characteristics that are considered biomimetic analogues of native ECM due to their dimensional similarities to natural collagen fibres $[174,175]$. These fibres meshes are usually produced by electrospinning, resulting in biomaterials with high porosity and surface area-to-volume ratios with potential applications in a wide range of tissue engineering strategies. However, they are typically based on polymeric biomaterials with limited bioactivity [175]. The incorporation of biological cues, such as BD, in their compositions has been proposed as a strategy that might promote cellular migration and proliferation, enabling an indirect control over cell behaviour [175]. The incorporation of biomolecules into electrospun nanofibers can be achieved by simple blending with the polymeric spinning solution or using emulsion and coaxial electrospinning strategies [176, 177]. As an example of these approaches, PL was blended with chitosan and poly(ethylene) oxide to produce electrospun nanofiber meshes [178]. Remarkably, the biological activity of PRP was not affected by the processing conditions. Although $70 \%$ of total protein content was released within 3 hours and the remaining content after 24 hours, the nanofibrous-PL 
membrane stimulated cell proliferation and, in formulations with higher concentration of PL, keratinocytes showed a more spread morphology, indicating a synergistic positive effect of nanotopography and biological cues. Liu and co-workers incorporated PRGF (using dextran as emulsion stabilizer) into polycaprolactone (PCL)/gelatin nanofibers by emulsion electrospinning technique in order to minimize the denaturation of PRGF proteins and increase the bioactivity of the scaffolds [179]. Although the release of bioactive GFs from the scaffold showed a burst in the first 24 hours, it lasted for nearly 30 days, resulting in improved proliferation and chemotactic effects on bone marrow MSCs, and more interestingly, promoted in vitro chondrogenic differentiation. The enhanced bioactivity of the scaffolds was also demonstrated in vivo in rabbit osteochondral defects, improving cartilage wound healing and suggesting to have antiinflammatory effects in the joint cavity.

The persistent presence of bacteria and endotoxins at the wound site is known to prolongs the inflammatory phase and may lead to chronic wound infections [180]. An injectable hydrogel system composed of chitosan and freeze-dried PG (calcium activated) combined with antibiotic nanoparticles (tigecycline) was explored as a convenient and effective therapeutic alternative to treat chronically infected wounds [181]. Tigecycline sustained release inhibited bacterial growth over time and reduced the inflammatory phase, whereas the addition of PG enhanced proliferation and migration of fibroblasts in vitro. Interestingly, other studies have also shown that the combination of $\mathrm{BD}$ with biomaterials might have a positive impact on resolving the subsequent inflammatory response occurring after their implantation. For example, PRGF (calcium activated) was impregnated into gelatin hydrogels incorporating micelles of sphingosine-1-phosphate agonist to induce macrophages recruitment [182]. Within 7 days, about $90 \%$ of TGF- $\beta 1$ and stromal cell derived factor-1 was delivered and both soluble factors were detectable 
after 14 days in vivo. Gelatin hydrogels incorporating micelles and PRGF recruited higher number of macrophages that lead to an initial increase of pro-inflammatory cytokines (TNF- $\alpha$ ) level, while 10 days after implantation they increased the production of antiinflammatory cytokines (IL-10 and TGF- $\beta 1$ ) and osteoprotegerin, an osteoclastogenesis inhibitory factor. Thus, sphingosine-1-phosphate agonist and PRGF showed a synergistic enhancement effect on the migration and recruitment of macrophages to the wound site that modulated the production of inflammatory mediators and induced granulation tissue formation and bone regeneration [182].

In order to recreate the biological gradients of the ECM, which are known to modulate the directional migration and overall cellular physiological behaviour [183], photocrosslinkable methacrylated gellan gum was combined with PL to generate concentration gradients of bioactive molecules along 3D hydrogel fibres produced by microfluidic strategies [184]. Using fibres containing inverse gradients of human umbilical vein endothelial cells and PL, it was shown that areas with lower PL content decreased cell viability whereas the PL-enriched section increased cell viability and induced cell adhesion and colonization after 12 hours and 7 days in culture. In a different approach, coating of hydroxyapatite/ $\beta$-tricalcium phosphate scaffolds with PL also showed to increase chemo-attraction and adhesion of MSCs and endothelial cells on the scaffold and to induce MSCs to produce and secrete pro-angiogenic proteins [185].

\subsubsection{Controlled architecture}

The regeneration of complex tissue interfaces has been explored by the combination of different materials in biphasic systems. These systems are designed to regenerate both the soft and hard regions of tissue interfaces by controlling the gradients of properties that define heterogeneous spatial microenvironments [186]. Bi-layered gelatin/ $\beta$-tricalcium 
phosphate sponges loaded with either MSCs, chondrocytes and L-PRP (chondrogenic layer) or MSCs and BMP-2 (osteogenic layer) were explored to repair osteochondral defects of the talus in horses [187]. This study demonstrated that the bilayer sponges combined with cell and biological factors promoted significantly higher osteochondral regeneration and reduced the defect size, as observed by radiography, quantitative computed tomography and macroscopic and histological evaluation 4 months after surgery, than the control group (unloaded bilayer sponges). In a similar approach, a bilayered system has been explored for the regeneration of periodontium in a critical 3wall intrabony periodontal defect in rats [188]. Calcium phosphate cement incorporating HA microspheres loaded with PL was used to promote the regeneration of alveolar bone side while PL-genipin self-crosslinking membrane was used for the regeneration of periodontal soft tissue. The combination of both systems was degraded within 6 weeks after implantation, showing a lower epithelial downgrowth and formation of periodontal ligament by the immobilization of PL proteins over the tooth root surface [188].

In recent years, advanced additive manufacturing technologies, such as $3 \mathrm{D}$ printing and bioprinting, have emerged in the field of TERM as fabrication strategies that have the potential to engineer patient personalized scaffolds and living constructs with finelytuned physicochemical properties and tailored components along defined positions of the 3D space [189]. As an example of the combination of these technologies with the incorporation of $\mathrm{BD}, 3 \mathrm{D}$ printed collagen/PCL/bioceramic scaffolds were explored to control the release of GFs from recombinant origin and from PRP [190]. After optimizing the composition and processing parameters that maximized the osteogenic potential of collagen/PCL biocomposite scaffolds and resulted in a sustained release of protein biomolecules (tested with BSA), the biomaterials were loaded with bioceramic, bioceramic/recombinant human BMP-2 or bioceramic/PRP. Interestingly, the sustained 
release of bioactive molecules from PRP-loaded formulation resulted in increased ALP activity, calcium deposition and osteocalcin activity by osteoblast-like-cells in comparison with other control groups, demonstrating that the proposed strategy might have the potential to enhance bone regeneration. In an attempt to recreate the different length scales and functions of native ECM, 3D printing (microscale control) was combined with other fabrication approaches such as layer-by-layer surface coating (nano/meso scale control) and freeze-drying (fibrillar structures) to produce 3D hierarchical scaffolds for bone tissue engineering [191]. Combining these different topdown and bottom-up methodologies, 3D printed structures based on PCL were coated by layer-by-layer assembly of marine-origin polysaccharides (carrageenan and chitosan) and PL, and subsequently freeze-dried to shape the layer-by-layer structures into nano/submicron-fibrils and nanocoatings. The sulphated and aminated nature of carrageenan and chitosan, respectively, increases the similarity to native ECM, being good candidates for the attraction and stabilization of GFs as mimetics of native glycosaminoglycans [192, 193]. Remarkably, the PCL- layer-by-layer -PL scaffolds could induce the osteogenesis of hASCs without relying on supplementation of culture media with osteogenic factors. The promising results of this methodology open the door to develop tunable PL hierarchical scaffolds to instruct stem cells towards different lineages.

\subsection{Selection of specific bioactive molecules}

The ability to control the delivery of specific bioactive molecules is highly important to precisely modulate the biological signals of the local cell microenvironment. The use of recombinant GFs in combination with finely engineered scaffolds might be a possible solution, however these are very expensive strategies having several technical and 
biological drawbacks [194]. Therefore, the components of BD, a cost-effective source of bioactive proteins, might be selectively and non-covalently bond to biomaterials constructs following different functionalization strategies.

Besides structural protein, ECM is composed of proteoglycans containing polysaccharides with different sulphation patterns which specifically interact with soluble bioactive molecules and regulates their availability and functionality within cellular microenvironment [144, 146]. For example, heparin, a highly sulphated glycosaminoglycan, is known to play a major role on the specific binding, sequestration and presentation of GFs containing heparin-binding domains [13]. In a recent work, PRP was combined with heparin-conjugated PLGA nanospheres and commercial fibrin gels [195]. This strategy prolonged the retention of heparin-binding GFs such as PDGF-BB ( $39 \%$ for formulations containing nanospheres $v s 88 \%$ for PRP control in the first $6 \mathrm{~h}$ ), while preserving their bioactivity. It is reasonable to expect that it might also have similar impact on the release profile of other heparin-binding GFs (e.g. FGF-2 and VEGF) present in PRP $[196,197]$. Furthermore, the proposed system showed superior healing outcomes, specifically dermal and epidermal regeneration and angiogenesis acceleration, as compared to the controls in a mouse skin wound model [195]. Moreover, PLGA degradation produces lactate that accelerates angiogenesis, activates pro-collagen factors and recruits endothelial progenitor cells to the wound site, which could have a synergistic positive impact on the obtained results [153]. Despite the obvious benefits of applying heparin as binding motif for certain GFs, the use of high doses of heparin is associated with several health risks due to its anticoagulant activity [198] that should not be disregarded in materials design.

The protein binding specificity of sulphated glycosaminoglycans is highly influenced by the sulphation position and patterns [199]. Therefore, the influence of charge and 
sulphation degree of different polysaccharides on the selective sequestration of bioactive molecules from BD have been studied using self-assembled PL-polysaccharide multilayered nanocoatings [200]. While the intermediate sulphated polysaccharide (1carrageenan) achieved high levels of FGF-2, VEGF and PDGF adsorption, the low sulphated polysaccharide ( $\kappa$-carrageenan) adsorbed high amounts of PDGF and intermediate levels of VEGF. On the other hand, heparin (highly sulphated) showed only high levels of VEGF adsorption while unsulphated polysaccharides (alginate and chitosan) general led to the adsorption of low levels of all tested GFs. These results highlight the potential of surface engineering strategies to selectively incorporate BD components into biomaterials and to modulate cell-material interactions. It is well known that the maintenance of adequate concentrations of appropriate biological factors is of key importance for the outcomes of the wound healing events. For example, the presence of the PDGF is important in MSCs proliferation, however its anti-morphogenic properties might impair the bone regrowth [201]. Therefore, in a regenerative approach, highly sulphated polymer-PL nanocoatings might be more adequate to promote the vascularization of tissue engineered constructs or to induce the vascular differentiation of stem cells since they lead to the incorporation of lower levels of PDGF and higher levels of VEGF than their less sulphated analogues [200]. This hypothesis has been tested in human umbilical vein endothelial cells, where the highly sulphated polysaccharides-PL nanocoatings induced cells to rapidly form tube-like structures accompanied by an increased expression of angiogenic associated genes [202].

The immobilization of antibodies on the surface of biomaterials to recognize and recruit specific GFs from BD is another design option being explored with impressive results. For example, Custódio and co-workers immobilized anti-PDGF-BB antibody on chitosan microparticles surface [203]. After incubation of the microparticles with PL, it 
was observed a significantly decrease of PDGF-BB (68\%) in the remaining PL solution, whereas the content of VEGF (18\%) and TGF- $\beta 1(20 \%)$ only registered a slight decrease, demonstrating the expected highly selective GF recruitment capability of this strategy. Furthermore, the proposed system allowed a faster attachment of hASCs, which lead to the formation of 3D constructs after 12 hours while control groups were not able to form stable aggregates. Similar approaches have been adopted for the immobilization of antibodies on the surface of electrospun nanofibers [177, 204]. With this strategy, it was possible to selective bind VEGF, TGF- $\beta 1$ or FGF-2 from a pool of proteins (PL) without affecting its bioactivity [204]. Furthermore, the simultaneous immobilization of multiple antibodies, distributed in a mixed or in a spatially controlled fashion, was also shown [204]. Although authors did not target any specific tissue, it can be foreseen that this strategy can be customized for specific regenerative medicine strategies, allowing, for example, the immobilization of GFs in a single or multiple binding approach, or the production of GFs patterns and gradients.

\subsection{Blood derivatives concentration}

The amount of BD delivered to the wound niche and, thus, bioactive molecules concentration, will affect the number of ligand-receptor events occurring in a given time frame and the extent of downstream intracellular signalling cascades driving tissue regeneration. Although, to the best of our knowledge, the specific GFs concentrations that trigger the regenerative pathways are not described yet, previous studies using PRP formulations in in vitro cultures, have reported that there is a dose-dependent effect of BD concentration on e.g. cell proliferation and differentiation [205], being therefore a

relevant parameter that should be optimized when combined with biomaterials. For instance, collagen/gelatin scaffolds were impregnated with reconstituted freeze-dried PL 
in order to study the optimal PL concentration ( $1 \mathrm{x}, 2 \mathrm{x}, 3 \mathrm{x}$, or $4 \mathrm{x}$ concentrated) to promote wound healing in vivo [206]. The release of GFs from the scaffolds increased in a concentration-dependent fashion and correlated with the scaffold degradation profile. Moreover, the $2 \mathrm{x}$ formulation effectively accelerated wound healing, enhancing cell proliferation and vessel growth in granulation tissue without obvious inflammatory reactions in a full-thickness skin defect. In a similar approach, gelatin sponges with different concentrations of PRGF (1x, 3x and 5x) were implanted in alveolar bone defects in rats and 3x PRGF sponges enhanced bone regeneration outcomes compared with the other formulations [207]. Remarkably, when PRP was used without the gelatin, it detached from the injury site and did not contribute to the regenerative process, evidencing the importance of biomaterials to allow the retention of $\mathrm{BD}$ at the injury site and the localized delivery of their signalling molecules.

More recently, photocrosslinkable methacrylated-HA hydrogels were blended with different concentrations of PL (0, 50 and 100\%) [63]. Both PL formulations exhibited a similar release profile, although the amount of total released protein was proportional to the initial amount of protein incorporated in the hydrogels. Surprisingly, the amount of FGF-2 released, after enzymatic degradation of the hydrogels, was negatively correlated with the initial protein loading. Similarly, PL incorporation positively impacted human periodontal ligament fibroblasts proliferation and metabolic activity. Furthermore, using the same system, it was possible to safely preserve and store hASCs and PL-derived GFs under standard cryopreservation protocols, showing the potential of this system as offthe-shelf injectable formulation [208].

The use of remote magnetic stimulation combine with magnetic responsive biomaterials might be a novel strategy to modulate the released kinetics in a timely and a controlled space that can potentiate the regenerative process [209]. For example, 
magnetic nanoparticles were incorporated in a methacrylated chondroitin sulphate hydrogel loaded with PL. Under magnetic stimulation, PDGF-BB release was faster and higher compared to the non-stimulated group. Besides enabling the localized control of GFs release, magnetic stimulation showed to modulate the swelling, matrix stability and degradation, which in combination with PL bioactivity, had a synergistic impact on cell morphology and synthesis of tendon- and bone-like matrix in an in vitro interfacial coculture model (hASCs and tendon-derived stem cells).

\subsection{Towards a clinical translation}

Previous in vitro and in vivo studies have consistently showed that the combination of $\mathrm{BD}$ with biomaterials might be a suitable strategy to modulate the delivery of their bioactive molecules and maximizes the synergistic biomaterial/BD therapeutic efficacy. Some of those therapeutic products are on the way to clinical translation. In this section, we review biomaterials loaded with $\mathrm{BD}$ that have been or are currently undergoing clinical studies for skin, maxillofacial, orthopaedic, and wound healing related applications. In a case report, three patients with chronic pressure ulcers were treated with PG (calcium activated) and PRP loaded in alginate beads for the sustained delivery of BD bioactive molecules [210]. Despite the small patient sample size, this approach increased granulation tissue in-growth and vascularity, improving wound healing. In a different case study, one patient with a two years nonhealing ulcer was treated with activated PRP covered by a gelatin sheet over 5 days [211]. The treatment improved granulation tissue formation over the wound. After thirty-three days, a new gelatin sheet impregnated with freeze-dried PRP was applied into the injury site, which healed without recurrent ulceration after 9 months. In the maxillofacial research area, a clinical study with ten patients used PG (thrombin and calcium activated) combined with MSCs and HA scaffold 
as a periodontal regenerative therapy for soft-tissue augmentation [212]. No adverse effects were observed during the follow-up time and all patients reported high satisfaction, demonstrating various degrees of regeneration and defect filling. The involvement of progenitor cells in this process might have an influence in the different outcomes. Currently, a randomized clinical trial (NCT03227367) composed of healthy individuals and chronic periodontitis patients is investigating biphasic calcium phosphate combined with PRF for inhibiting osteoclasts differentiation and bone loss [213].

Some commercial products using BD in combination of biomaterials are already approved and distributed for musculoskeletal disorders. One example is Vergenix ${ }^{\mathrm{TM}}$ STR (CollPlant Ltd., Ness-Ziona, Israel) composed of plant derived recombinant human type I collagen mixed with PRP for lateral epicondylitis [214]. In the clinical trial, the product showed to have a clinical success rate $(>25 \%$ improvement in pain and motion) significantly better than corticosteroids or PRP (standard treatments) and reduction in pain and recovery of motion using standard evaluation methodology at 3 months and 6 months post treatment. Another commercial product, BST-CarGel ${ }^{\circledR}$ (Smith and Nephew, MA, USA), is composed of chitosan gel and PRP (uncoagulated) [215]. This medical device is used to stabilize the microfracture-based blood clot (standard and first-line surgical treatment) and it was shown to be an effective mid-term cartilage repair treatment, having a significantly higher therapeutic outcome compared with the microfracture alone in a randomized controlled clinical trial. 


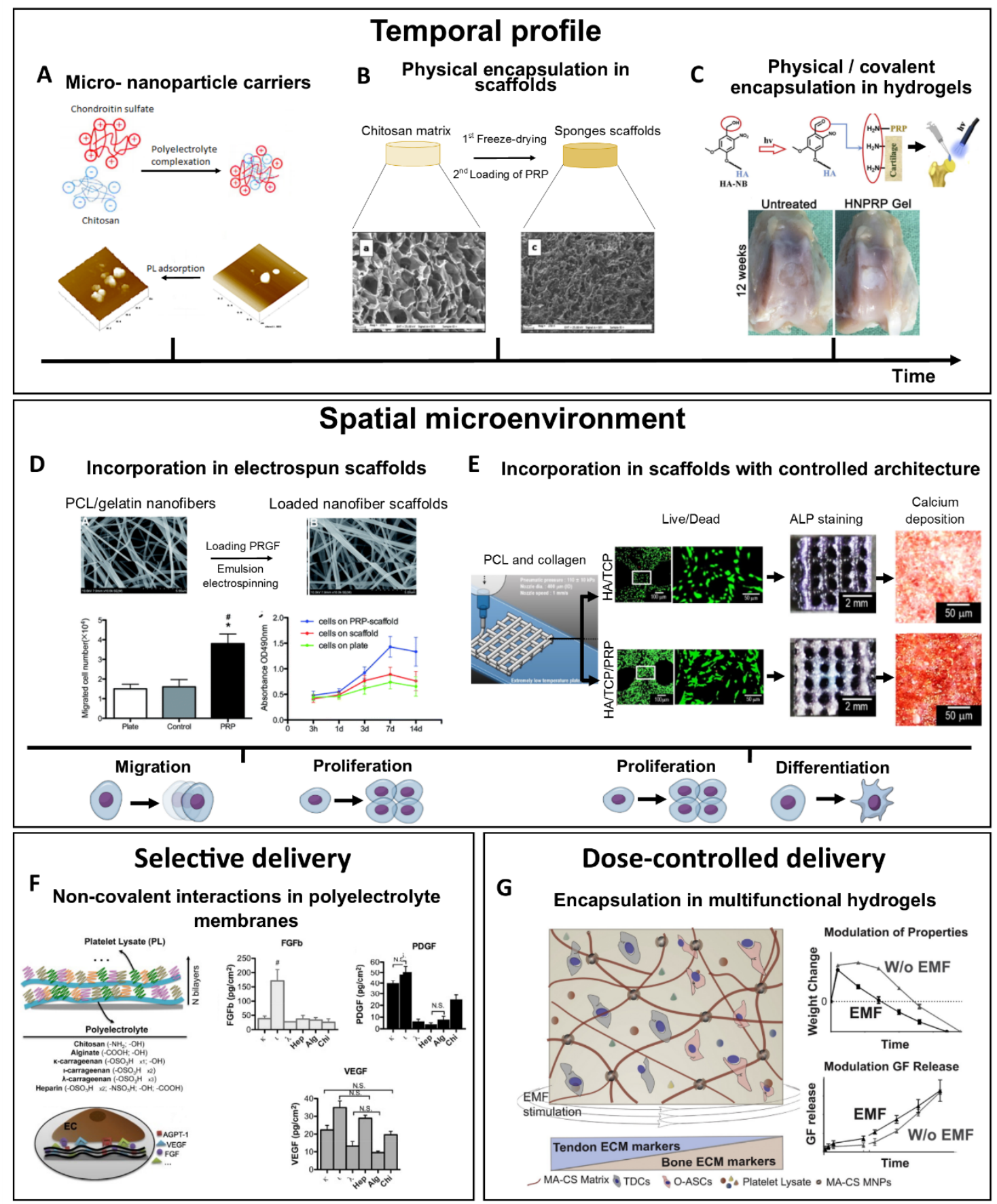

Figure 3. Strategies incorporating blood derivatives into biomaterials in order to modulate BD temporal profile: A) PL was loaded into chitosan/chondroitin sulphate nanoparticles, adapted from [105]. Copyright 2012, John Wiley and Sons. B) PRP was loaded into sponges composed of chitosan, reproduced with permission [164]. Copyright 2013, John Wiley and Sons. C) PRP was covalent crosslinked and physical encapsulated 
into modified HA injectable hydrogels. Reproduced with permission [168]. The control over cellular spatial distribution by D) PRGF proteins incorporation in electrospun meshes, reproduced with permission [179]. Copyright 2017, Elsevier. E) PRP incorporated into 3D printed polycaprolactone scaffold, reproduced with permission [190]. Copyright 2017, Elsevier. Finally, the modulation of selective bioactive molecules by EF) polysaccharides presenting different sulphation degrees and charges, reproduced with permission [200]. Copyright 2015, Elsevier. BD concentration-dependent delivery by G) PL incorporation in magnetic responsive hydrogels, reproduced with permission [209]. Copyright 2017, Elsevier.

Table 3. Summary of the most relevant preclinical studies using combinations of BD with biomaterials. Abbreviations: PRP (platelet rich-plasma); HA (hyaluronic acid); L-PRP (leukocyte PRP); PRGF (platelet rich-in growth factors); PCL (polycaprolactone); FG (fibrin gel); Pl (platelet lysate). 


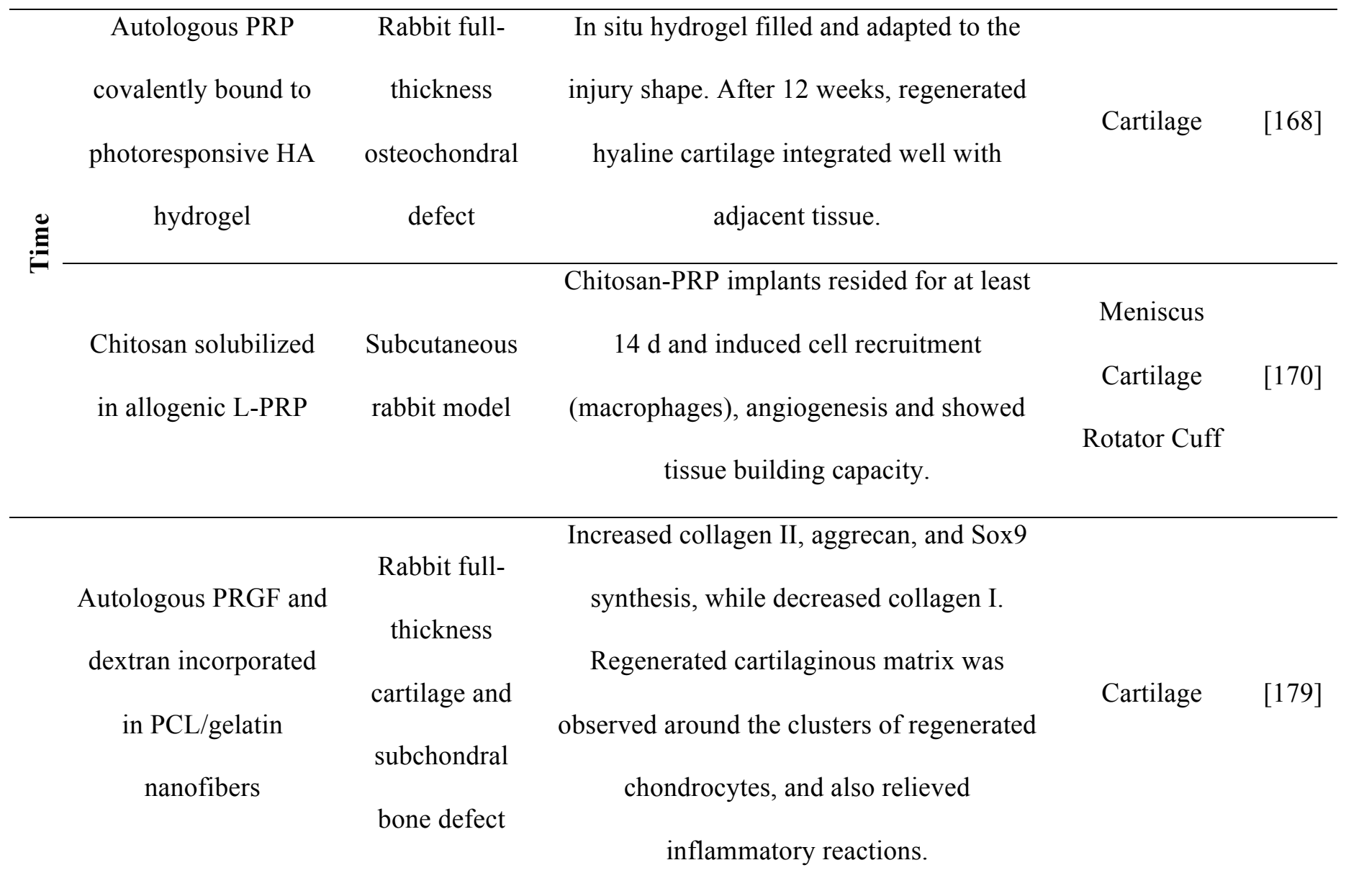

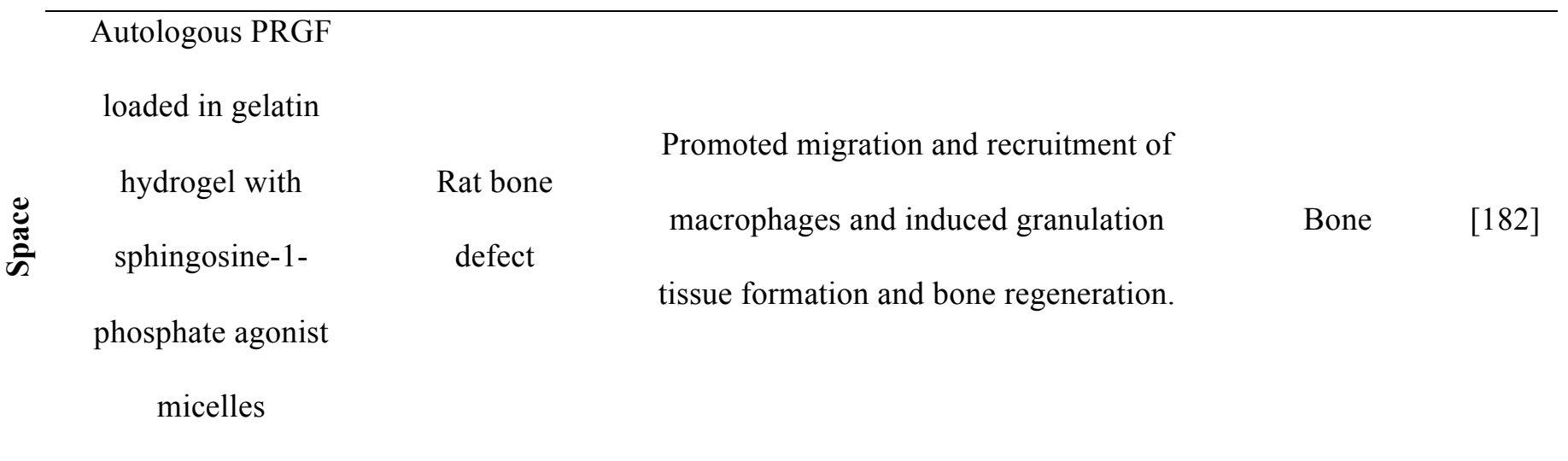

\section{Bilayer sponges:} gelatin/ $\beta$-tricalcium phosphate loaded with MSCs, chondrocytes and autologous L-PRP osteochondral defect Equine fullthickness
4 months after surgery, the defects were or MSCs and BMP-2. covered with smooth white tissue. The upper part was filled with cartilage-like tissue and better bone regeneration was observed in the lower part.
Joint disorder

(Osteochondro

[187] 
Bi-layered system:

allogeneic PL loaded

in calcium phosphate

cement with HA-

microspheres and

PL-genipin
The construct was completely degraded

Rat critical 3- after 6 weeks and was substituted by highly

wall intrabony vascularized aligned connective tissue. It

periodontal restricted the formation of long epithelial

Alveolar bone

[188]

junctions and enabled the formation of defect

periodontal ligament.

\begin{tabular}{ccc}
\hline & Autologous PRP with & Mouse skin \\
& FG loaded in heparin- & \\
& & wound model \\
id & conjugated PLGA & \\
& nanospheres
\end{tabular}

Allogeneic freeze-

dried PL (1x, 2x, 3x, or $4 \mathrm{x}$ concentrated)

Mouse full-

Enhanced keratinocyte migration, superior

healing properties (dermal and epidermal

regeneration) and angiogenesis

acceleration.

$2 \mathrm{x}$ formulation effectively accelerated
Skin wound healing, enhancing cell proliferation Skin (dermisthickness skin impregnated in

collagen/gelatin defect like tissue) without obvious inflammatory reactions scaffolds

Autologous PRGF

$(1 \mathrm{x}, 3 \mathrm{x}$ and $5 \mathrm{x}$ concentrated) impregnated in gelatin Rat alveolar 3x PRGF hydrogel increased new bone bone defect regeneration.

Alveolar bone [207] sponges

\section{Concluding remarks and future directions}

The use of BD from autologous sources as therapeutic strategies, particularly targeting the regeneration of musculoskeletal tissues, rapidly moved into clinical trials due to their inherent advantages in terms of translation potential. However, these efforts to rapidly translate fundamental science into medical applications lead to the poor 
understanding of the biological and cellular mechanisms behind their use. The need for standardization of PRP preparation methods continues to be a common argument raised to explain discrepancies among studies and the lack of efficacy of some PRP based therapies in clinical settings [216-218]. While standardization issues may be solved by the definition of good manufacturing practice protocols that generate reproducible BD formulations and the use of platelets from a pool of donors, establishment of clear relationships between the overwhelming numbers of bioactive molecules present in different BD formulations with the resulting therapeutic effects may be a herculean task. As highlighted in this review, the development of more controllable systems for the delivery of a well characterized population of bioactive molecules to target cell niches will certainly improve many clinical aspects behind the use of BD.

The combination of BD with biomaterials has emerged as a synergistic strategy to modulate the selective spatio-temporal and dose-controlled release of signalling molecules that will orchestrate the swing between tissue regeneration and scar formation. Taking in consideration the complex microenvironment present in wound healing, the codelivery of several bioactive molecules (e.g. GFs and cytokines) from BD will most likely result in a more efficient regenerative microenvironment than the delivery of a single type of biomolecule. To date, most of the proposed strategies to deliver and release BD in a temporal controlled fashion relied on the use of nano- microparticulate systems as carriers. These systems enabled the delivery of encapsulated bioactive molecules in short periods (hours), showing a temporary effect. In a bottom-up strategy, the physical encapsulation of $\mathrm{BD}$ in sponges and hydrogels showed to prolong the release (weeks to months) of biomolecules, enhancing their stability and therapeutic efficiency. Implementing these relatively simple strategies, it is possible to modulate the release profile of different biomolecules by the rational selection of biomaterials (tuning the 
matrix/biomolecule interactions) and by controlling their degradation rates. However, most of these systems remain as proof-of-concept, since their design considerations and physicochemical properties still require further optimization. In particular, it is necessary to add control over the delivery of multiple bioactive factors at distinct release kinetics in order to enable a dynamic temporal release that matches with the wound healing events.

Regarding the spatial coordination, we have considered systems where the incorporation of $\mathrm{BD}$ influences cell fate towards tissue regeneration, mainly cellular migration, proliferation and differentiation. For example, in 3D hydrogel fibres, BD increased cellular colonization and adhesion to the biomaterials as well as cell viability. However, these systems have limitations in terms of mimicking the native tissues complexity and wound healing microenvironment (different cells types, signalling molecules and biochemical/biomechanical properties). The advent of 3D printing/bioprinting technologies in TERM applications might help to overcome some of the reported limitations by enabling to fabricate customized constructs with precise 3D patterns of different biomaterials, cells and signalling molecules [189]. At the moment, only a few studies explored the potential of these fabrication techniques in combination with BD as bioinstructive cues. Therefore, this is an interesting research topic open to be explored in which we foresee major developments in the near future.

The selective delivery of biomolecules from BD can be modulated by different strategies, including the non-covalent immobilization within biomaterial nanocoatings (mimicking the natural interactions occurring in the ECM) or by the covalent functionalization of the biomaterial surface with antibodies, which enables the specific binding of targeted bioactive molecules. In particular, due to their inherent high molecular specificity and affinity, the bioconjugation of antibodies to biomaterials is a promising approach to selectively bind GFs of interest and modulate cell fate, avoiding the 
conflicting co-delivery of bioactive molecules with opposite roles that might have an undesired outcome, such as anti-morphogenic (e.g. PDGF-BB) and morphogenic factors (e.g. VEGF). Antibodies immobilization has however several limitations that hider their practical application and clinical translation such as high cost, low shelf stability or the associated immunological risk for humans [219]. In order to explore the full potential of GFs sequestering biomaterials in combination with $\mathrm{BD}$, molecular imprinting method can create in synthetic polymers selective recognition sites for a specific molecular template, resulting in materials that mimic antibody combining sites [220, 221]. By exploring the molecular imprinting technology, it would be conceptually feasible to produce intelligent biomaterials able to remove undesired components or selectively recruit the bioactive molecules of interest (single or multiple) from a pool of proteins (BD). Another important aspect in order to modulate the selective delivery of GFs is the processing of BD. Fibrinogen present in different BD formulations and coagulation cascade inductors will have a marked impact over the physical properties of the resulting fibrin matrix and the ability to retain and present GFs [59]. Moreover, this will also affect the downstream temporal platelet degranulation profile (fast with thrombin and slow with calcium) [169]. Thus, different activation strategies will affect GFs bioavailability which will lead to differences in wound healing process $[163,222]$ and to various effects at cellular level [61].

Due to the emerging research highlighting the importance of cell-derived exosomes in tissue development and homeostasis regulation [223], the use of platelet-derived exosomes could be a simple and safe alternative to modulate tissue regeneration. However, despite their promising benefits, there is still a lack of comprehension on the biological relevance of the activation process to produce populations with defined cargos, which should be addressed in future research. Additionally, in the authors opinion, future 
studies should also invest more research efforts on studying the release profile of multiple therapeutic molecules (GFs, cytokines and others bioactive molecules) in order to improve the general understanding on the affinities between the biological cues of BD and biomaterial matrices. This data would provide the necessary knowledge to rationally select systems that enable a tissue-specific spatio-temporal, selective and dose-dependent release profile of bioactive molecules present on $\mathrm{BD}$, more than only controlling the quantity of GFs that is loaded.

Currently, the major challenge in the field is the translation of these approaches to clinical use. Clinical cases are based in small study samples that showed heterogeneous degree of regeneration, thus, being difficult to understand the potential of each formulation. Despite the fast translation of $\mathrm{BD}$ to clinical use, the combination with biomaterials is challenging, because they require an approval as new biomaterial-based products, even when using materials already approved in other applications due to the different properties and possible different outcomes [224]. Although, this process will necessarily slow its translation to the clinics, in our opinion, it is the right direction in order to get the best of BD's therapeutic potential.

Major advances have been made over the recent years to develop these systems, but there remain a number of challenges that will need to be addressed in the future. As a strategic pipeline, the definition of good manufacturing practice protocols to standardize the production method of $\mathrm{BD}$ formulations, together with the continuous understanding of the basic biology of BD in wound healing modulation will provide robust and reproducible therapeutic results.. Moreover, specifically designed biomaterials incorporating $\mathrm{BD}$ that bind to and sequester biomolecules, and the full understanding of the nature of these interactions will enable engineering the wound healing environment towards tissue regeneration. 


\section{Conflict of interest}

Authors declare no competing interest.

\section{Acknowledgements}

BBM acknowledges the financial support from FCT/MCTES (Fundação para a Ciência e a Tecnologia/ Ministério da Ciência, Tecnologia, e Ensino Superior) and the Fundo Social Europeu através do Programa Operacional do Capital Humano (FSE/POCH), PD/59/2013 for PD/BD/113807/2015. MGF acknowledges European Union's Horizon 2020 research and innovation programme under the Marie Skłodowska-Curie grant agreement No 706996. PB acknowledges RECOGNIZE and NORTE2020 (UTAPICDT/CTM-BIO/0023/2014). RMD acknowledges SFRH/BPD/112459/2015.

\section{References}

[1] S.A. Eming, P. Martin, M. Tomic-Canic, Wound repair and regeneration: mechanisms, signaling, and translation, Sci. Transl. Med. 6 (2014) 265-266.

[2] G.C. Gurtner, S. Werner, Y. Barrandon, M.T. Longaker, Wound repair and regeneration, Nature. 453 (2008) 314-321.

[3] G.C. Gurtner, M.J. Callaghan, M.T. Longaker, Progress and potential for regenerative medicine, Annu. Rev. Med. 58 (2007) 299-312.

[4] J.A. Hubbell, Biomaterials in tissue engineering, Nat. Biotechnol. 13 (1995) 565-576.

[5] R. Langer, J. Vacanti, Advances in tissue engineering, J. Pediatr. Surg. 51 (2016) 812. 
[6] S. Padilla, M. Sánchez, G. Orive, E. Anitua, Human-Based Biological and Biomimetic Autologous Therapies for Musculoskeletal Tissue Regeneration, Trends Biotechnol. (2016).

[7] A. Mishra, J. Woodall, A. Vieira, Treatment of tendon and muscle using platelet-rich plasma, Clin. Sports Med. 28 (2009) 113-125.

[8] Y. Zhu, M. Yuan, H. Meng, A. Wang, Q. Guo, Y. Wang, J. Peng, Basic science and clinical application of platelet-rich plasma for cartilage defects and osteoarthritis: a review, Osteoarthr. Cartil. 21 (2013) 1627-1637.

[9] P.S. Babo, R.L. Reis, M.E. Gomes, Periodontal tissue engineering: current strategies and the role of platelet rich hemoderivatives, J. Mater. Chem. 5 (2017) 3617-3628.

[10] R.J. Miron, M. Fujioka-Kobayashi, M. Bishara, Y. Zhang, M. Hernandez, J. Choukroun, Platelet-rich fibrin and soft tissue wound healing: a systematic review, Tissue Eng. Part B Rev. 23 (2017) 83-99.

[11] R.-J. de Vos, J. Windt, A. Weir, Strong evidence against platelet-rich plasma injections for chronic lateral epicondylar tendinopathy: a systematic review, Br. J. Sports Med. 48 (2014) 952-956.

[12] V.Y. Moraes, M. Lenza, M.J. Tamaoki, F. Faloppa, J.C. Belloti, Platelet-rich therapies for musculoskeletal soft tissue injuries, Cochrane Database Syst Rev. 12 (2013) CD010071.

[13] I. Capila, R.J. Linhardt, Heparin-protein interactions, Angew. Chem. Int. Ed. Engl. $41(2002) 390-412$.

[14] L. Macri, D. Silverstein, R.A. Clark, Growth factor binding to the pericellular matrix and its importance in tissue engineering, Adv. Drug Deliv. Rev. 59 (2007) 1366-1381. [15] A. Atala, D.J. Irvine, M. Moses, S. Shaunak, Wound healing versus regeneration: role of the tissue environment in regenerative medicine, MRS Bull. 35 (2010) 597-606. 
[16] A.J. Singer, R.A. Clark, Cutaneous wound healing, N. Engl. J. Med. 341 (1999) 738746.

[17] E.R. Zielins, D.A. Atashroo, Z.N. Maan, D. Duscher, G.G. Walmsley, O. Marecic, M. Hu, K. Senarath-Yapa, A. McArdle, R. Tevlin, Wound healing: an update, Regen. Med. 9 (2014) 817-830.

[18] G.Y. Chen, G. Nuñez, Sterile inflammation: sensing and reacting to damage, Nat. Rev. Immunol. 10 (2010) 826-837.

[19] R. Shechter, M. Schwartz, CNS sterile injury: just another wound healing?, Trends Mol. Med. 19 (2013) 135-143.

[20] S.E. Hankinson, W.C. Willett, G.A. Colditz, D.J. Hunter, D.S. Michaud, B. Deroo, B. Rosner, F.E. Speizer, M. Pollak, Circulating concentrations of insulin-like growth factor I and risk of breast cancer, Lancet. 351 (1998) 1393-1396.

[21] G.L. Hortin, D. Sviridov, N.L. Anderson, High-abundance polypeptides of the human plasma proteome comprising the top 4 logs of polypeptide abundance, Clin. Chem. 54 (2008) 1608-1616.

[22] M.H. Klinger, W. Jelkmann, Role of blood platelets in infection and inflammation, J. Interferon Cytokine Res. 22 (2002) 913-922.

[23] M.R. Thomas, R.F. Storey, The role of platelets in inflammation, J. Thromb. Haemost. 114 (2015) 449-458.

[24] A.T. Nurden, Platelets, inflammation and tissue regeneration, Drug Deliv. Transl. Res. 105 (2011) S13-33.

[25] S. Barrientos, O. Stojadinovic, M.S. Golinko, H. Brem, M. Tomic-Canic, Growth factors and cytokines in wound healing, Wound Repair Regen. 16 (2008) 585-601.

[26] A.T. Nurden, P. Nurden, M. Sanchez, I. Andia, E. Anitua, Platelets and wound healing, Front. Biosci. 13 (2008) 3532-3548. 
[27] E.M. Golebiewska, A.W. Poole, Platelet secretion: From haemostasis to wound healing and beyond, Blood Rev. 29 (2015) 153-162.

[28] P. Martin, S.J. Leibovich, Inflammatory cells during wound repair: the good, the bad and the ugly, Trends Cell Biol. 15 (2005) 599-607.

[29] D.M. Mosser, J.P. Edwards, Exploring the full spectrum of macrophage activation, Nat. Rev. Immunol. 8 (2008) 958-969.

[30] T.A. Wynn, A. Chawla, J.W. Pollard, Macrophage biology in development, homeostasis and disease, Nature. 496 (2013) 445-455.

[31] L. Li, B. Yan, Y.-Q. Shi, W.-Q. Zhang, Z.-L. Wen, Live imaging reveals differing roles of macrophages and neutrophils during zebrafish tail fin regeneration, J. Biol. Chem. 287 (2012) 25353-25360.

[32] A.L. Mescher, A.W. Neff, Regenerative capacity and the developing immune system, Regen. Med. (2005) 39-66.

[33] S.A. Eming, T. Krieg, J.M. Davidson, Inflammation in wound repair: molecular and cellular mechanisms, J. Invest. Dermatol. 127 (2007) 514-525.

[34] B. Behm, P. Babilas, M. Landthaler, S. Schreml, Cytokines, chemokines and growth factors in wound healing, J. Eur. Acad. Dermatol. Venereol. 26 (2012) 812-820.

[35] B. Hinz, S.H. Phan, V.J. Thannickal, A. Galli, M.-L. Bochaton-Piallat, G. Gabbiani, The myofibroblast: one function, multiple origins, J. Pathol. 170 (2007) 1807-1816.

[36] T. Wynn, Cellular and molecular mechanisms of fibrosis, J. Pathol. 214 (2008) 199210.

[37] T.A. Wynn, T.R. Ramalingam, Mechanisms of fibrosis: therapeutic translation for fibrotic disease, Nat. Med. 18 (2012) 1028-1040.

[38] A. Page-McCaw, A.J. Ewald, Z. Werb, Matrix metalloproteinases and the regulation of tissue remodelling, Nat. Rev. Mol. Cell Biol. 8 (2007) 221-233. 
[39] A. Leask, D.J. Abraham, TGF- $\beta$ signaling and the fibrotic response, FASEB J. 18 (2004) 816-827.

[40] R. Montesano, L. Orci, Transforming growth factor beta stimulates collagen-matrix contraction by fibroblasts: implications for wound healing, Proc. Natl. Acad. Sci. USA. 85 (1988) 4894-4897.

[41] P.-J. Wipff, D.B. Rifkin, J.-J. Meister, B. Hinz, Myofibroblast contraction activates latent TGF- $\beta 1$ from the extracellular matrix, J. Cell Biol. 179 (2007) 1311-1323.

[42] K. Riedel, F. Riedel, U.R. Goessler, G. Germann, M. Sauerbier, TGF- $\beta$ Antisense Therapy Increases Angiogenic Potential in Human Keratinocytes In Vitro, Arch. Med. Res. 38 (2007) 45-51.

[43] P.B. Saadeh, B.J. Mehrara, D.S. Steinbrech, M.E. Dudziak, J.A. Greenwald, J.S. Luchs, J.A. Spector, H. Ueno, G.K. Gittes, M.T. Longaker, Transforming growth factor$\beta 1$ modulates the expression of vascular endothelial growth factor by osteoblasts, Am. J. Physiol., Cell Physiol. 277 (1999) C628-C637.

[44] M. Shah, D.M. Foreman, M. Ferguson, Neutralisation of TGF-beta 1 and TGF-beta 2 or exogenous addition of TGF-beta 3 to cutaneous rat wounds reduces scarring, J. Cell. Sci. 108 (1995) 985-1002.

[45] S. Levenson, E. Geever, L. Crowley, J. Oates III, C. Berard, H. Rosen, Healing of rat skin wounds, Annals of Surgery. 161 (1965) 293-308.

[46] S.J. Forbes, N. Rosenthal, Preparing the ground for tissue regeneration: from mechanism to therapy, Nat. Med. 20 (2014) 857-869.

[47] H. Lu, D. Huang, N. Saederup, I.F. Charo, R.M. Ransohoff, L. Zhou, Macrophages recruited via CCR2 produce insulin-like growth factor-1 to repair acute skeletal muscle injury, FASEB J. 25 (2011) 358-369. 
[48] M. Saclier, H. Yacoub-Youssef, A.L. Mackey, L. Arnold, H. Ardjoune, M. Magnan, F. Sailhan, J. Chelly, G.K. Pavlath, R. Mounier, M. Kjaer, B. Chazaud, Differentially Activated Macrophages Orchestrate Myogenic Precursor Cell Fate During Human Skeletal Muscle Regeneration, STEM CELLS. 31 (2013) 384-396.

[49] B.-S. Ding, D.J. Nolan, J.M. Butler, D. James, A.O. Babazadeh, Z. Rosenwaks, V. Mittal, H. Kobayashi, K. Shido, D. Lyden, T.N. Sato, S.Y. Rabbany, S. Rafii, Inductive angiocrine signals from sinusoidal endothelium are required for liver regeneration, Nature. 468 (2010) 310-315.

[50] C. Preeja, S. Arun, Platelet-rich fibrin: Its role in periodontal regeneration, Saudi J. Dent. Res. 5 (2014) 117-122.

[51] E. Anitua, M. Sanchez, A.T. Nurden, P. Nurden, G. Orive, I. Andia, New insights into and novel applications for platelet-rich fibrin therapies, Trends Biotechnol. 24 (2006) $227-234$.

[52] E. Anitua, R. Prado, S. Padilla, G. Orive, Platelet-rich plasma scaffolds for tissue engineering: more than just growth factors in three dimensions, Platelets. 26 (2015) 281282.

[53] F.M. Chen, Y. An, R. Zhang, M. Zhang, New insights into and novel applications of release technology for periodontal reconstructive therapies, J. Control Release. 149 (2011) 92-110.

[54] R.E. Marx, Platelet-rich plasma: evidence to support its use, J. Oral Maxillofac. Surg. 62 (2004) 489-496.

[55] E. Anitua, R. Prado, M. Azkargorta, E. Rodriguez-Suarez, I. Iloro, J. Casado-Vela, F. Elortza, G. Orive, High-throughput proteomic characterization of plasma rich in growth factors (PRGF-Endoret)-derived fibrin clot interactome, J. Tissue Eng. Regen. M. 9 (2015) E1-E12. 
[56] R.E. Marx, Platelet-rich plasma (PRP): what is PRP and what is not PRP?, Implant Dent. 10 (2001) 225-228.

[57] I.B. Copland, M.A. Garcia, E.K. Waller, J.D. Roback, J. Galipeau, The effect of platelet lysate fibrinogen on the functionality of MSCs in immunotherapy, Biomaterials. 34 (2013) 7840-7850.

[58] M.B. Zucker, M.W. Mosesson, M.J. Broekman, K.L. Kaplan, Release of platelet fibronectin (cold-insoluble globulin) from alpha granules induced by thrombin or collagen; lack of requirement for plasma fibronectin in ADP-induced platelet aggregation, Blood. 54 (1979) 8-12.

[59] J.W. Weisel, R.I. Litvinov, Mechanisms of fibrin polymerization and clinical implications, Blood. 121 (2013) 1712-1719.

[60] D.M. Dohan Ehrenfest, L. Rasmusson, T. Albrektsson, Classification of platelet concentrates: from pure platelet-rich plasma (P-PRP) to leucocyte- and platelet-rich fibrin (L-PRF), Trends Biotechnol. 27 (2009) 158-167.

[61] I. Andia, N. Maffulli, Platelet-rich plasma for managing pain and inflammation in osteoarthritis, Nat. Rev. Rheumatol. . 9 (2013) 721-730.

[62] E. Anitua, R. Alonso, C. Girbau, J.J. Aguirre, F. Muruzabal, G. Orive, Antibacterial effect of plasma rich in growth factors (PRGF(R)-Endoret(R)) against Staphylococcus aureus and Staphylococcus epidermidis strains, Clin. Exp. Dermatol. 37 (2012) 652-657. [63] P.S. Babo, R.L. Pires, L. Santos, A. Franco, F. Rodrigues, I.B. Leonor, R.L. Reis, M.E. Gomes, Platelet Lysate-Loaded Photocrosslinkable Hyaluronic Acid Hydrogels for Periodontal Endogenous Regenerative Technology, ACS Biomater. Sci. Eng. (2016).

[64] T. Burnouf, M.L. Chou, Y.W. Wu, C.Y. Su, L.W. Lee, Antimicrobial activity of platelet (PLT)-poor plasma, PLT-rich plasma, PLT gel, and solvent/detergent-treated PLT lysate biomaterials against wound bacteria, Transfusion. 53 (2013) 138-146. 
[65] R.M.B. Yeaman, S. A., Antimicrobial peptides from platelets, Drug Resist. Updat. 2 (1999) 116-126.

[66] J. Krijgsveld, S.A. Zaat, J. Meeldijk, P.A. van Veelen, G. Fang, B. Poolman, E. Brandt, J.E. Ehlert, A.J. Kuijpers, G.H. Engbers, J. Feijen, J. Dankert, Thrombocidins, microbicidal proteins from human blood platelets, are C-terminal deletion products of CXC chemokines, J. Biol. Chem. 275 (2000) 20374-20381.

[67] F.W. Lam, K.V. Vijayan, R.E. Rumbaut, Platelets and their interactions with other immune cells, Compr. Physiol. 5 (2015) 1265-1280.

[68] K. Krauel, C. Weber, S. Brandt, U. Zahringer, U. Mamat, A. Greinacher, S. Hammerschmidt, Platelet factor 4 binding to lipid A of Gram-negative bacteria exposes PF4/heparin-like epitopes, Blood. 120 (2012) 3345-3352.

[69] H. Hamzeh-Cognasse, P. Damien, A. Chabert, B. Pozzetto, F. Cognasse, O. Garraud, Platelets and infections - complex interactions with bacteria, Front. Immunol. 6 (2015) 82.

[70] D. M Dohan Ehrenfest, T. Bielecki, R. Jimbo, G. Barbe, M. Del Corso, F. Inchingolo, G. Sammartino, Do the fibrin architecture and leukocyte content influence the growth factor release of platelet concentrates? An evidence-based answer comparing a pure platelet-rich plasma (P-PRP) gel and a leukocyte-and platelet-rich fibrin (L-PRF), Curr. Pharm. Biotechnol. 13 (2012) 1145-1152.

[71] M. Sánchez, E. Anitua, I. Andia, Poor standardization in platelet-rich therapies hampers advancement, Arthroscopy. 26 (2010) 725-726.

[72] G. Weibrich, W.K. Kleis, G. Hafner, W.E. Hitzler, Growth factor levels in plateletrich plasma and correlations with donor age, sex, and platelet count, J. Craniomaxillofac. Surg. 30 (2002) 97-102. 
[73] D. Man, H. Plosker, J.E. Winland-Brown, The use of autologous platelet-rich plasma (platelet gel) and autologous platelet-poor plasma (fibrin glue) in cosmetic surgery, Plast. Reconstr. Surg. 107 (2001) 229-239.

[74] P.R. Amable, R.B. Carias, M.V. Teixeira, I. da Cruz Pacheco, R.J. Correa do Amaral, J.M. Granjeiro, R. Borojevic, Platelet-rich plasma preparation for regenerative medicine: optimization and quantification of cytokines and growth factors, Stem Cell Res. Ther. 4 (2013) 67.

[75] I. Hatakeyama, E. Marukawa, Y. Takahashi, K. Omura, Effects of platelet-poor plasma, platelet-rich plasma, and platelet-rich fibrin on healing of extraction sockets with buccal dehiscence in dogs, Tissue Eng. Part A. 20 (2014) 874-882.

[76] D.M. Ranly, J. McMillan, T. Keller, C.H. Lohmann, T. Meunch, D.L. Cochran, Z. Schwartz, B.D. Boyan, Platelet-derived growth factor inhibits demineralized bone matrix-induced intramuscular cartilage and bone formation. A study of immunocompromised mice, J. Bone Joint Surg. Am. 87 (2005) 2052-2064.

[77] D.M. Dohan Ehrenfest, I. Andia, M.A. Zumstein, C.Q. Zhang, N.R. Pinto, T. Bielecki, Classification of platelet concentrates (Platelet-Rich Plasma-PRP, Platelet-Rich Fibrin-PRF) for topical and infiltrative use in orthopedic and sports medicine: current consensus, clinical implications and perspectives, Muscles Ligaments Tendons J. 4 (2014) 3-9.

[78] I. Martineau, E. Lacoste, G. Gagnon, Effects of calcium and thrombin on growth factor release from platelet concentrates: kinetics and regulation of endothelial cell proliferation, Biomaterials. 25 (2004) 4489-4502.

[79] M.R. Messora, M.J. Nagata, R.C. Dornelles, S.R. Bomfim, F.A. Furlaneto, L.G. de Melo, T.M. Deliberador, A.F. Bosco, V.G. Garcia, S.E. Fucini, Bone healing in critical- 
size defects treated with platelet-rich plasma activated by two different methods. A histologic and histometric study in rat calvaria, J. Periodontal Res. 43 (2008) 723-729. [80] G. Intini, S. Andreana, F.E. Intini, R.J. Buhite, L.A. Bobek, Calcium sulfate and platelet-rich plasma make a novel osteoinductive biomaterial for bone regeneration, J. Transl. Med. 5 (2007) 13.

[81] M. Matsui, Y. Tabata, Enhanced angiogenesis by multiple release of platelet-rich plasma contents and basic fibroblast growth factor from gelatin hydrogels, Acta Biomater. 8 (2012) 1792-1801.

[82] H.-L. Wang, G. Avila, Platelet Rich Plasma: Myth or Reality?, Eur. J. Dent. 1 (2007) 192-194.

[83] I. Pallotta, J.A. Kluge, J. Moreau, R. Calabrese, D.L. Kaplan, A. Balduini, Characteristics of platelet gels combined with silk, Biomaterials. 35 (2014) 3678-3687. [84] R. Crespo-Diaz, A. Behfar, G.W. Butler, D.J. Padley, M.G. Sarr, J. Bartunek, A.B. Dietz, A. Terzic, Platelet lysate consisting of a natural repair proteome supports human mesenchymal stem cell proliferation and chromosomal stability, Cell Transplant. 20 (2011) 797-811.

[85] N. Fekete, M. Gadelorge, D. Furst, C. Maurer, J. Dausend, S. Fleury-Cappellesso, V. Mailander, R. Lotfi, A. Ignatius, L. Sensebe, P. Bourin, H. Schrezenmeier, M.T. Rojewski, Platelet lysate from whole blood-derived pooled platelet concentrates and apheresis-derived platelet concentrates for the isolation and expansion of human bone marrow mesenchymal stromal cells: production process, content and identification of active components, Cytotherapy. 14 (2012) 540-554.

[86] J.M. DeLong, R.P. Russell, A.D. Mazzocca, Platelet-rich plasma: the PAW classification system, Arthroscopy. 28 (2012) 998-1009. 
[87] J. Magalon, O. Bausset, N. Serratrice, L. Giraudo, H. Aboudou, J. Veran, G. Magalon, F. Dignat-Georges, F. Sabatier, Characterization and comparison of 5 plateletrich plasma preparations in a single-donor model, Arthroscopy. 30 (2014) 629-638.

[88] G. Weibrich, T. Hansen, W. Kleis, R. Buch, W.E. Hitzler, Effect of platelet concentration in platelet-rich plasma on peri-implant bone regeneration, Bone. 34 (2004) $665-671$.

[89] P. Bajaj, A.R. Pradeep, E. Agarwal, N.S. Rao, S.B. Naik, N. Priyanka, N. Kalra, Comparative evaluation of autologous platelet-rich fibrin and platelet-rich plasma in the treatment of mandibular degree II furcation defects: a randomized controlled clinical trial, J. Periodontal Res. 48 (2013) 573-581.

[90] G. Weibrich, W.K. Kleis, W.E. Hitzler, G. Hafner, Comparison of the platelet concentrate collection system with the plasma-rich-in-growth-factors kit to produce platelet-rich plasma: a technical report, Int. J. Oral Maxillofac. Implants. 20 (2005) 118123.

[91] P.A. Everts, J. Hoffmann, G. Weibrich, C.B. Mahoney, J.P. Schonberger, A. van Zundert, J.T. Knape, Differences in platelet growth factor release and leucocyte kinetics during autologous platelet gel formation, Transfus. Med. 16 (2006) 363-368.

[92] C.F. Nathan, Secretory products of macrophages, J. Clin. Invest. 79 (1987) 319-326.

[93] G.A. Duque, A. Descoteaux, Macrophage cytokines: involvement in immunity and infectious diseases, Frontiers in immunology. 5 (2014).

[94] M. Lech, H.-J. Anders, Macrophages and fibrosis: How resident and infiltrating mononuclear phagocytes orchestrate all phases of tissue injury and repair, Biochim. Biophys. Acta. 1832 (2013) 989-997. 
[95] E. Anitua, M.M. Zalduendo, M.H. Alkhraisat, G. Orive, Release kinetics of plateletderived and plasma-derived growth factors from autologous plasma rich in growth factors, Ann. Anat. 195 (2013) 461-466.

[96] W. Yin, X. Qi, Y. Zhang, J. Sheng, Z. Xu, S. Tao, X. Xie, X. Li, C. Zhang, Advantages of pure platelet-rich plasma compared with leukocyte- and platelet-rich plasma in promoting repair of bone defects, J. Transl. Med. 14 (2016) 73.

[97] Y. Zhou, J. Zhang, H. Wu, M.V. Hogan, J.H. Wang, The differential effects of leukocyte-containing and pure platelet-rich plasma (PRP) on tendon stem/progenitor cells-implications of PRP application for the clinical treatment of tendon injuries, Stem Cell Res. Ther. 6 (2015) 173.

[98] M.M. Martino, P.S. Briquez, A. Ranga, M.P. Lutolf, J.A. Hubbell, Heparin-binding domain of fibrin(ogen) binds growth factors and promotes tissue repair when incorporated within a synthetic matrix, Proc. Natl. Acad. Sci. U. S. A. 110 (2013) 45634568.

[99] D. Fufa, B. Shealy, M. Jacobson, S. Kevy, M.M. Murray, Activation of platelet-rich plasma using soluble type I collagen, J. Oral Maxillofac. Surg. 66 (2008) 684-690.

[100] A. Kalén, O. Wahlström, C.H. Linder, P. Magnusson, The content of bone morphogenetic proteins in platelets varies greatly between different platelet donors, Biochem. Biophys. Res. Commun. 375 (2008) 261-264.

[101] H.H. Luu, W.X. Song, X. Luo, D. Manning, J. Luo, Z.L. Deng, K.A. Sharff, A.G. Montag, R.C. Haydon, T.C. He, Distinct roles of bone morphogenetic proteins in osteogenic differentiation of mesenchymal stem cells, J. Orthop. Res. 25 (2007) 665-677. [102] M. Beederman, J.D. Lamplot, G. Nan, J. Wang, X. Liu, L. Yin, R. Li, W. Shui, H. Zhang, S.H. Kim, W. Zhang, J. Zhang, Y. Kong, S. Denduluri, M.R. Rogers, A. Pratt, 
R.C. Haydon, H.H. Luu, J. Angeles, L.L. Shi, T.C. He, BMP signaling in mesenchymal stem cell differentiation and bone formation, J. Biomed. Sci. Eng. 6 (2013) 32-52.

[103] T.M. Fortunato, C. Beltrami, C. Emanueli, P.A. De Bank, G. Pula, Platelet lysate gel and endothelial progenitors stimulate microvascular network formation in vitro: tissue engineering implications, Sci. Rep. 6 (2016) 25326.

[104] M. Bernardi, F. Agostini, K. Chieregato, E. Amati, C. Durante, M. Rassu, M. Ruggeri, S. Sella, E. Lombardi, M. Mazzucato, G. Astori, The production method affects the efficacy of platelet derivatives to expand mesenchymal stromal cells in vitro, J. Transl. Med. 15 (2017) 90.

[105] V.E. Santo, M.E. Gomes, J.F. Mano, R.L. Reis, Chitosan-chondroitin sulphate nanoparticles for controlled delivery of platelet lysates in bone regenerative medicine, J.Tissue Eng. Regen. Med. 6 (2012) s47-59.

[106] P.S. Babo, V.E. Santo, M.E. Gomes, R.L. Reis, Development of an Injectable Calcium Phosphate/Hyaluronic Acid Microparticles System for Platelet Lysate Sustained Delivery Aiming Bone Regeneration, Macromol. Biosci. 16 (2016) 1662-1677.

[107] P.S. Babo, X. Cai, A.S. Plachokova, R.L. Reis, J.A. Jansen, M.E. Gomes, X.F. Walboomers, The Role of a Platelet Lysate-Based Compartmentalized System as a Carrier of Cells and Platelet-Origin Cytokines for Periodontal Tissue Regeneration, Tissue Eng. Part A. 22 (2016) 1164-1175.

[108] T. Burnouf, D. Strunk, M.B.C. Koh, K. Schallmoser, Human platelet lysate: Replacing fetal bovine serum as a gold standard for human cell propagation?, Biomaterials. 76 (2016) 371-387.

[109] J. Choukroun, F. Adda, C. Schoeffer, A. Vervelle, PRF: An opportunity in perioimplantology (in French), Implantodontie. 42 (2000) 55-62. 
[110] D.M. Dohan, J. Choukroun, A. Diss, S.L. Dohan, A.J. Dohan, J. Mouhyi, B. Gogly, Platelet-rich fibrin (PRF): a second-generation platelet concentrate. Part I: technological concepts and evolution, Oral Surg. Oral Med. Oral Pathol. Oral Radiol. Endod. 101 (2006) e37-44.

[111] S. Nishimoto, K. Fujita, Y. Sotsuka, M. Kinoshita, T. Fujiwara, K. Kawai, M. Kakibuchi, Growth Factor Measurement and Histological Analysis in Platelet Rich Fibrin: A Pilot Study, J. Maxillofac. Oral Surg. 14 (2015) 907-913.

[112] B. Chignon-Sicard, C.A. Georgiou, E. Fontas, S. David, P. Dumas, T. Ihrai, E. Lebreton, Efficacy of leukocyte- and platelet-rich fibrin in wound healing: a randomized controlled clinical trial, Plast. Reconstr. Surg. 130 (2012) 819e-829e.

[113] W. Pluemsakunthai, S. Kuroda, H. Shimokawa, S. Kasugai, A basic analysis of platelet-rich fibrin: distribution and release of platelet-derived growth factor-BB, Inflam. and Regen. 33 (2013) 164-172.

[114] E. Torreggiani, F. Perut, L. Roncuzzi, N. Zini, S.R. Baglio, N. Baldini, Exosomes: novel effectors of human platelet lysate activity, Eur. Cell Mater. 28 (2014) 137-151.

[115] M.T. Aatonen, T. Ohman, T.A. Nyman, S. Laitinen, M. Gronholm, P.R. Siljander, Isolation and characterization of platelet-derived extracellular vesicles, J. Extracell. Vesicles. 3 (2014).

[116] S.C. Guo, S.C. Tao, W.J. Yin, X. Qi, T. Yuan, C.Q. Zhang, Exosomes derived from platelet-rich plasma promote the re-epithelization of chronic cutaneous wounds via activation of YAP in a diabetic rat model, Theranostics. 7 (2017) 81-96.

[117] N. Arraud, R. Linares, S. Tan, C. Gounou, J.M. Pasquet, S. Mornet, A.R. Brisson, Extracellular vesicles from blood plasma: determination of their morphology, size, phenotype and concentration, J. Thromb. Haemost. 12 (2014) 614-627. 
[118] S.J. Kim, D.H. Song, J.W. Park, S. Park, S.J. Kim, Effect of Bone Marrow Aspirate Concentrate-Platelet-Rich Plasma on Tendon-Derived Stem Cells and Rotator Cuff Tendon Tear, Cell Transplant. 26 (2017) 867-878.

[119] O. Gidlof, M. van der Brug, J. Ohman, P. Gilje, B. Olde, C. Wahlestedt, D. Erlinge, Platelets activated during myocardial infarction release functional miRNA, which can be taken up by endothelial cells and regulate ICAM1 expression, Blood. 121 (2013) 39083917, S3901-3926.

[120] J. Li, M. Tan, Q. Xiang, Z. Zhou, H. Yan, Thrombin-activated platelet-derived exosomes regulate endothelial cell expression of ICAM-1 via microRNA-223 during the thrombosis-inflammation response, Thromb. Res. 154 (2017) 96-105.

[121] I. Arbesu, M. Bucsaiova, M.B. Fischer, C. Mannhalter, Platelet-borne complement proteins and their role in platelet-bacteria interactions, J. Thromb. Haemost. 14 (2016) $2241-2252$

[122] P. Harrison, E.M. Cramer, Platelet $\alpha$-granules, Blood Rev. 7 (1993) 52-62.

[123] P. Blair, R. Flaumenhaft, Platelet $\alpha$-granules: basic biology and clinical correlates, Blood Rev. 23 (2009) 177-189.

[124] A. McNicol, J.M. Gerrard, Post-receptor events associated with thrombin-induced platelet activation, Blood Coagul. Fibrinolysis. 4 (1993) 975-991.

[125] M. Aatonen, M. Grönholm, P.R.-M. Siljander, Platelet-derived microvesicles: multitalented participants in intercellular communication, in: Semin. Thromb. Hemost., Thieme Medical Publishers, 2012, pp. 102-113.

[126] E.J. Goetzl, L. Goetzl, J.S. Karliner, N. Tang, L. Pulliam, Human plasma plateletderived exosomes: effects of aspirin, FASEB J. 30 (2016) 2058-2063. 
[127] H.J. Huber, P. Holvoet, Exosomes: emerging roles in communication between blood cells and vascular tissues during atherosclerosis, Curr. Opin. Lipidol. 26 (2015) 412-419.

[128] V.A. Fadok, D.L. Bratton, A. Konowal, P.W. Freed, J.Y. Westcott, P.M. Henson, Macrophages that have ingested apoptotic cells in vitro inhibit proinflammatory cytokine production through autocrine/paracrine mechanisms involving TGF-beta, PGE2, and PAF, J. Clin. Invest. 101 (1998) 890-898.

[129] S.G. Boswell, B.J. Cole, E.A. Sundman, V. Karas, L.A. Fortier, Platelet-rich plasma: a milieu of bioactive factors, Arthroscopy. 28 (2012) 429-439.

[130] M.O. Schär, J. Diaz-Romero, S. Kohl, M.A. Zumstein, D. Nesic, Platelet-rich concentrates differentially release growth factors and induce cell migration in vitro, Clin. Orthop. Relat. Res. 473 (2015) 1635-1643.

[131] G.A. Duque, A. Descoteaux, Macrophage cytokines: involvement in immunity and infectious diseases, Front. Immunol. 5 (2014) 491.

[132] B.L. Eppley, J.E. Woodell, J. Higgins, Platelet Quantification and Growth Factor Analysis from Platelet-Rich Plasma: Implications for Wound Healing, Plast. Reconstr. Surg. 114 (2004) 1502-1508.

[133] P. Hofbauer, S. Riedl, K. Witzeneder, F. Hildner, S. Wolbank, M. Groeger, C. Gabriel, H. Redl, W. Holnthoner, Human platelet lysate is a feasible candidate to replace fetal calf serum as medium supplement for blood vascular and lymphatic endothelial cells, Cytotherapy. 16 (2014) 1238-1244.

[134] E. Anitua, I. Andí, M. Sanchez, J. Azofra, M. del Mar Zalduendo, M. de la Fuente, P. Nurden, A.T. Nurden, Autologous preparations rich in growth factors promote proliferation and induce VEGF and HGF production by human tendon cells in culture, J. Orthop. Res. 23 (2005) 281-286. 
[135] M.P. Mojica-Henshaw, P. jacobson, J. Morris, L. Kelley, J. Pierce, M. Boyer, J.-A. Reems, Serum-converted platelet lysate can substitute for fetal bovine serum in human mesenchymal stromal cell cultures, Cytotherapy. 15 (2013) 1458-1468.

[136] H.S. Cho, I.H. Song, S.-Y. Park, M.C. Sung, M.-W. Ahn, K.E. Song, Individual Variation in Growth Factor Concentrations in Platelet-rich Plasma and Its Influence on Human Mesenchymal Stem Cells, Korean J. Lab. Med. 31 (2011) 212-218.

[137] H. El-Sharkawy, A. Kantarci, J. Deady, H. Hasturk, H. Liu, M. Alshahat, T.E. Van Dyke, Platelet-Rich Plasma: Growth Factors and Pro- and Anti-Inflammatory Properties, J. Periodontol. 78 (2007) 661-669.

[138] A. Roffi, G. Filardo, E. Assirelli, C. Cavallo, A. Cenacchi, A. Facchini, B. Grigolo, E. Kon, E. Mariani, L. Pratelli, L. Pulsatelli, M. Marcacci, Does platelet-rich plasma freeze-thawing influence growth factor release and their effects on chondrocytes and synoviocytes?, Biomed. Res. Int. 2014 (2014) 692913.

[139] J. Qiao, N. An, X. Ouyang, Quantification of growth factors in different platelet concentrates, Platelets. 28 (2017) 774-778.

[140] D.E. Roberts, A. McNicol, R. Bose, Mechanism of Collagen Activation in Human Platelets, J. Biol. Chem. 279 (2004) 19421-19430.

[141] A.C. Brown, T.H. Barker, Fibrin-based biomaterials: Modulation of macroscopic properties through rational design at the molecular level, Acta Biomater. 10 (2014) 15021514.

[142] J.J. Rice, M.M. Martino, L. De Laporte, F. Tortelli, P.S. Briquez, J.A. Hubbell, Engineering the regenerative microenvironment with biomaterials, Adv. Healthc. Mater. $2(2013) 57-71$.

[143] S. Reed, B. Wu, Sustained growth factor delivery in tissue engineering applications, Ann. Biomed. Eng. 42 (2014) 1528-1536. 
[144] K. Lee, E.A. Silva, D.J. Mooney, Growth factor delivery-based tissue engineering: general approaches and a review of recent developments, J. R. Soc. Interface. 8 (2011) 153-170.

[145] P. Tayalia, D.J. Mooney, Controlled growth factor delivery for tissue engineering, Adv. Mater. 21 (2009) 3269-3285.

[146] L. Uebersax, H.P. Merkle, L. Meinel, Biopolymer-based growth factor delivery for tissue repair: from natural concepts to engineered systems, Tissue Eng. Part B Rev. 15 (2009) 263-289.

[147] A.C. Mitchell, P.S. Briquez, J.A. Hubbell, J.R. Cochran, Engineering growth factors for regenerative medicine applications, Acta Biomater. 30 (2016) 1-12.

[148] H.S. Azevedo, I. Pashkuleva, Biomimetic supramolecular designs for the controlled release of growth factors in bone regeneration, Adv. Drug Deliv. Rev. 94 (2015) 63-76. [149] Y. Li, Y. Xiao, C. Liu, The horizon of materiobiology: A perspective on materialguided cell behaviors and tissue engineering, Chem. Rev. 117 (2017) 4376-4421.

[150] S. Shanbhag, A. Stavropoulos, S. Suliman, T. Hervig, K. Mustafa, Efficacy of humanized mesenchymal stem cell cultures for bone tissue engineering: a systematic review with a focus on platelet-derivatives, Tissue Eng. Part B Rev. (2017).

[151] K. Bieback, Platelet lysate as replacement for fetal bovine serum in mesenchymal stromal cell cultures, Transfus. Med. Hemother. 40 (2013) 326-335.

[152] E.A. Masoudi, J. Ribas, G. Kaushik, J. Leijten, A. Khademhosseini, Platelet-rich blood derivatives for stem cell-based tissue engineering and regeneration, Stem Cell Reports. 2 (2016) 33-42.

[153] G. Gainza, S. Villullas, J.L. Pedraz, R.M. Hernandez, M. Igartua, Advances in drug delivery systems (DDSs) to release growth factors for wound healing and skin regeneration, Nanomedicine. 11 (2015) 1551-1573. 
[154] S. van Rijt, P. Habibovic, Enhancing regenerative approaches with nanoparticles, J. R. Soc. Interface. 14 (2017) 20170093.

[155] M.B. Oliveira, J.F. Mano, Polymer-based microparticles in tissue engineering and regenerative medicine, Biotechnol. Prog. 27 (2011) 897-912.

[156] E.-c. Shen, T.C. Chou, C.H. Gau, H.P. Tu, Y.T. Chen, E. Fu, Releasing growth factors from activated human platelets after chitosan stimulation: A possible bio-material for platelet-rich plasma preparation,

Clin. Oral Implants Res. 17 (2006) 572-578.

[157] K. Kojima, Y. Okamoto, K. Kojima, K. Miyatake, H. Fujise, Y. Shigemasa, S. Minami, Effects of chitin and chitosan on collagen synthesis in wound healing, J. Vet. Med. Sci. 66 (2004) 1595-1598.

[158] F.T. Bosman, I. Stamenkovic, Functional structure and composition of the extracellular matrix, J. Pathol. 200 (2003) 423-428.

[159] V.E. Santo, E.G. Popa, J.F. Mano, M.E. Gomes, R.L. Reis, Natural assembly of platelet lysate-loaded nanocarriers into enriched 3D hydrogels for cartilage regeneration, Acta Biomater. 19 (2015) 56-65.

[160] V.E. Santo, A.R.C. Duarte, E.G. Popa, M.E. Gomes, J.F. Mano, R.L. Reis, Enhancement of osteogenic differentiation of human adipose derived stem cells by the controlled release of platelet lysates from hybrid scaffolds produced by supercritical fluid foaming, J. Control. Rel. 162 (2012) 19-27.

[161] J.M. Burkhart, M. Vaudel, S. Gambaryan, S. Radau, U. Walter, L. Martens, J. Geiger, A. Sickmann, R.P. Zahedi, The first comprehensive and quantitative analysis of human platelet protein composition allows the comparative analysis of structural and functional pathways, Blood. 120 (2012) e73-e82. 
[162] D.Y. Arifin, L.Y. Lee, C.-H. Wang, Mathematical modeling and simulation of drug release from microspheres: implications to drug delivery systems, Adv. Drug Deliv. Rev. 58 (2006) 1274-1325.

[163] M.M. Martino, P.S. Briquez, A. Ranga, M.P. Lutolf, J.A. Hubbell, Heparin-binding domain of fibrin (ogen) binds growth factors and promotes tissue repair when incorporated within a synthetic matrix, Proc. Natl. Acad. Sci. U.S.A. 110 (2013) 45634568.

[164] B. Kutlu, T. Aydın, R. Seda, A.C. Akman, M. Gümüşderelioglu, R.M. Nohutcu, Platelet-rich plasma-loaded chitosan scaffolds: Preparation and growth factor release kinetics, J. Biomed. Mater. Res. B Appl. Biomater. 101 (2013) 28-35.

[165] M. Mori, S. Rossi, F. Ferrari, M.C. Bonferoni, G. Sandri, F. Riva, M. Tenci, C. Del Fante, G. Nicoletti, C. Caramella, Sponge-like dressings based on the association of chitosan and sericin for the treatment of chronic skin ulcers. II. Loading of the hemoderivative platelet lysate, J. Pharm. Sci. . 105 (2016) 1188-1195.

[166] B.V. Slaughter, S.S. Khurshid, O.Z. Fisher, A. Khademhosseini, N.A. Peppas, Hydrogels in regenerative medicine, Adv. Mater. 21 (2009) 3307-3329.

[167] Y.S. Zhang, A. Khademhosseini, Advances in engineering hydrogels, Science. 356 (2017) eaaf3627.

[168] X. Liu, Y. Yang, X. Niu, Q. Lin, B. Zhao, Y. Wang, L. Zhu, An in situ photocrosslinkable platelet rich plasma-Complexed hydrogel glue with growth factor controlled release ability to promote cartilage defect repair, Acta Biomater. (2017) 179187.

[169] T.E. Foster, B.L. Puskas, B.R. Mandelbaum, M.B. Gerhardt, S.A. Rodeo, Plateletrich plasma: from basic science to clinical applications, Am. J. Sports Med. 37 (2009) 2259-2272. 
[170] A. Chevrier, V. Darras, G. Picard, M. Nelea, D. Veilleux, M. Lavertu, C. Hoemann, M. Buschmann, Injectable chitosan-platelet-rich plasma (PRP) implants to promote tissue regeneration: In vitro properties, in vivo residence, degradation, cell recruitment and vascularization, J. Tissue Eng. Regen. Med. (2017).

[171] S. Kuttappan, K.S. Keyan, M.B. Nair, Evaluation of osteoinductive and endothelial differentiation potential of Platelet-Rich Plasma incorporated GelatinNanohydroxyapatite Fibrous Matrix, J. Biomed. Mater. Res. B Appl. Biomater. 104 (2016) $771-781$.

[172] D.H.R. Kempen, L. Lu, A. Heijink, T.E. Hefferan, L.B. Creemers, A. Maran, M.J. Yaszemski, W.J.A. Dhert, Effect of local sequential VEGF and BMP-2 delivery on ectopic and orthotopic bone regeneration, Biomaterials. 30 (2009) 2816-2825.

[173] J. Leijten, J. Seo, K. Yue, G. Trujillo-de Santiago, A. Tamayol, G.U. Ruiz-Esparza, S.R. Shin, R. Sharifi, I. Noshadi, M.M. Álvarez, Y.S. Zhang, A. Khademhosseini, Spatially and temporally controlled hydrogels for tissue engineering, Mater. Sci. Eng. R. Rep. 119 (2017) 1-35.

[174] J. Yao, C.W. Bastiaansen, T. Peijs, High strength and high modulus electrospun nanofibers, Fibers. 2 (2014) 158-186.

[175] S. Khorshidi, A. Solouk, H. Mirzadeh, S. Mazinani, J.M. Lagaron, S. Sharifi, S. Ramakrishna, A review of key challenges of electrospun scaffolds for tissue-engineering applications, J. Tissue Eng. Regen. Med. 10 (2016) 715-738.

[176] S. Sahoo, L.T. Ang, J.C.H. Goh, S.L. Toh, Growth factor delivery through electrospun nanofibers in scaffolds for tissue engineering applications, J. Biomed. Mater. Res. A. 93 (2010) 1539-1550.

[177] J.S. Choi, H.S. Kim, H.S. Yoo, Electrospinning strategies of drug-incorporated nanofibrous mats for wound recovery, Drug Deliv. Transl. Res. 5 (2015) 137-145. 
[178] V. Bertoncelj, J. Pelipenko, J. Kristl, M. Jeras, M. Cukjati, P. Kocbek, Development and bioevaluation of nanofibers with blood-derived growth factors for dermal wound healing, Eur. J. Pharm. Biopharm. 88 (2014) 64-74.

[179] J. Liu, H. Nie, Z. Xu, F. Guo, S. Guo, J. Yin, Y. Wang, C. Zhang, Construction of PRP-containing nanofibrous scaffolds for controlled release and their application to cartilage regeneration, J. Mater. Chem. 3 (2015) 581-591.

[180] S.a. Guo, L.A. DiPietro, Factors affecting wound healing, J. Dent. Res. 89 (2010) 219-229.

[181] T. Nimal, G. Baranwal, M. Bavya, R. Biswas, R. Jayakumar, Anti-staphylococcal Activity of Injectable Nano Tigecycline/Chitosan-PRP Composite Hydrogel Using Drosophila melanogaster Model for Infectious Wounds, ACS Appl. Mater. Interfaces. 8 (2016) 22074-22083.

[182] Y.-H. Kim, H. Furuya, Y. Tabata, Enhancement of bone regeneration by dual release of a macrophage recruitment agent and platelet-rich plasma from gelatin hydrogels, Biomaterials. 35 (2014) 214-224.

[183] N.F. Huang, S. Li, Regulation of the matrix microenvironment for stem cell engineering and regenerative medicine, Ann. Biomed. Eng. 39 (2011) 1201-1214.

[184] V.E. Santo, P. Babo, M. Amador, C.u. Correia, B.r. Cunha, D.F. Coutinho, N.M. Neves, J.o.F. Mano, R.L. Reis, M.E. Gomes, Engineering Enriched Microenvironments with Gradients of Platelet Lysate in Hydrogel Fibers, Biomacromolecules. 17 (2016) 1985-1997.

[185] J. Leotot, L. Coquelin, G. Bodivit, P. Bierling, P. Hernigou, H. Rouard, N. Chevallier, Platelet lysate coating on scaffolds directly and indirectly enhances cell migration, improving bone and blood vessel formation, Acta Biomater. 9 (2013) 66306640 
[186] B.D. Smith, D.A. Grande, The current state of scaffolds for musculoskeletal regenerative applications, Nat. Rev. Rheumatol. . 11 (2015) 213-222.

[187] J.-p. Seo, T. Tanabe, N. Tsuzuki, S. Haneda, K. Yamada, H. Furuoka, Y. Tabata, N. Sasaki, Effects of bilayer gelatin/ $\beta$-tricalcium phosphate sponges loaded with mesenchymal stem cells, chondrocytes, bone morphogenetic protein-2, and platelet rich plasma on osteochondral defects of the talus in horses, Res. Vet. Sci. 95 (2013) 12101216.

[188] P.S. Babo, X. Cai, A.S. Plachokova, R.L. Reis, J. Jansen, M.E. Gomes, X.F. Walboomers, Evaluation of a platelet lysate bi-layered system for periodontal regeneration in a rat intrabony 3 -wall periodontal defect, J. Tissue Eng. Regen. Med.

[189] M.E. Gomes, M.T. Rodrigues, R.M. Domingues, R.L. Reis, Tissue Engineering and Regenerative Medicine: New Trends and Directions-A Year in Review, Tissue Eng. Part B Rev. 23 (2017) 211-224.

[190] W. Kim, C.H. Jang, G. Kim, Optimally designed collagen/polycaprolactone biocomposites supplemented with controlled release of $\mathrm{HA} / \mathrm{TCP} / \mathrm{rhBMP}-2$ and HA/TCP/PRP for hard tissue regeneration, Mater. Sci. Eng. C Mater. Biol. Appl. 78 (2017) 763-772.

[191] S.M. Oliveira, R.L. Reis, J.o.F. Mano, Assembling human platelet lysate into multiscale 3D scaffolds for bone tissue engineering, ACS Biomater. Sci. Eng. 1 (2014) 2-6.

[192] J. Folkman, Y. Shing, Control of angiogenesis by heparin and other sulfated polysaccharides, in: D.A. Lane, Björk, I., Lindahl, U. (Ed.) Heparin and related polysaccharides, Springer Science \& Business Media., New York, 1992, pp. 355-364. 
[193] I. Vlodavsky, H.-Q. Miao, B. Medalion, P. Danagher, D. Ron, Involvement of heparan sulfate and related molecules in sequestration and growth promoting activity of fibroblast growth factor, Cancer and Metastasis Rev. 15 (1996) 177-186.

[194] J.E. Babensee, L.V. McIntire, A.G. Mikos, Growth factor delivery for tissue engineering, Pharm. Res. 17 (2000) 497-504.

[195] W.G. La, H.S. Yang, Heparin-Conjugated Poly (Lactic-Co-Glycolic Acid) Nanospheres Enhance Large-Wound Healing by Delivering Growth Factors in PlateletRich Plasma, Artif. Organs. 39 (2015) 388-394.

[196] M. Klagsbrun, The affinity of fibroblast growth factors (FGFs) for heparin; FGFheparan sulfate interactions in cells and extracellular matrix, Curr. Opin. Cell Biol. 2 (1990) 857-863.

[197] J.R. Bishop, M. Schuksz, J.D. Esko, Heparan sulphate proteoglycans fine-tune mammalian physiology, Nature. 446 (2007) 1030-1037.

[198] J. Hirsh, T.E. Warkentin, S.G. Shaughnessy, S.S. Anand, J.L. Halperin, R. Raschke, C. Granger, E.M. Ohman, J.E. Dalen, Heparin and low-molecular-weight heparin mechanisms of action, pharmacokinetics, dosing, monitoring, efficacy, and safety, Chest. 119 (2001) 64S-94S.

[199] J. Valcarcel, R. Novoa-Carballal, R.I. Pérez-Martín, R.L. Reis, J.A. Vázquez, Glycosaminoglycans from marine sources as therapeutic agents, Biotechnol. Adv. 35 (2017) 711-725.

[200] S.M. Oliveira, V.E. Santo, M.E. Gomes, R.L. Reis, J.F. Mano, Layer-by-layer assembled cell instructive nanocoatings containing platelet lysate, Biomaterials. 48 (2015) 56-65. 
[201] D.M. Ranly, C.H. Lohmann, D. Andreacchio, B.D. Boyan, Z. Schwartz, Plateletrich plasma inhibits demineralized bone matrix-induced bone formation in nude mice, JBJS. 89 (2007) 139-147.

[202] S.M. Oliveira, R.P. Pirraco, A.P. Marques, V.E. Santo, M.E. Gomes, R.L. Reis, J.F. Mano, Platelet lysate-based pro-angiogenic nanocoatings, Acta Biomater. 32 (2016) 129137.

[203] C.A. Custódio, V.E. Santo, M.B. Oliveira, M.E. Gomes, R. Reis, J. Mano, Functionalized microparticles producing scaffolds in combination with cells, Adv. Funct. Mater. 24 (2014) 1391-1400.

[204] C. Oliveira, A.R. Costa-Pinto, R.L. Reis, A. Martins, N.M. Neves, Biofunctional nanofibrous substrate comprising immobilized antibodies and selective binding of autologous growth factors, Biomacromolecules. 15 (2014) 2196-2205.

[205] J. Han, H. Meng, J. Tang, S. Li, Y. Tang, Z. Chen, The effect of different plateletrich plasma concentrations on proliferation and differentiation of human periodontal ligament cells in vitro, Cell Prolif. 40 (2007) 241-252.

[206] R. Ito, N. Morimoto, L.H. Pham, T. Taira, K. Kawai, S. Suzuki, Efficacy of the controlled release of concentrated platelet lysate from a collagen/gelatin scaffold for dermis-like tissue regeneration, Tissue Eng. Part A. 19 (2013) 1398-1405.

[207] D. Nakajima, Y. Tabata, S. Sato, Periodontal tissue regeneration with PRP incorporated gelatin hydrogel sponges, Biomed. Mater. 10 (2015) 055016.

[208] L.S. Neves, P.S. Babo, A.I. Gonçalves, R. Costa-Almeida, S.G. Caridade, J.F. Mano, R.M. Domingues, M.T. Rodrigues, R.L. Reis, M.E. Gomes, Injectable Hyaluronic Acid Hydrogels Enriched with Platelet Lysate as a Cryostable Off-the-Shelf System for Cell-Based Therapies, Regen. Eng. Transl. Med. 3 (2017) 53-69. 
[209] E.D. Silva, P.S. Babo, R. Costa-Almeida, R.M. Domingues, B.B. Mendes, E. Paz, P. Freitas, M.T. Rodrigues, P.L. Granja, M.E. Gomes, Multifunctional magneticresponsive hydrogels to engineer tendon-to-bone interface, Nanomedicine. (2017) 3010830109.

[210] S.A. Sell, J.J. Ericksen, T.W. Reis, L.R. Droste, M.B. Bhuiyan, D.R. Gater, A case report on the use of sustained release platelet-rich plasma for the treatment of chronic pressure ulcers, J. Spinal Cord. Med. 34 (2011) 122-127.

[211] N. Morimoto, N. Kakudo, T. Ogura, T. Hara, M. Matsui, M. Yamamoto, Y. Tabata, K. Kusumoto, Easy-to-Use Preservation and Application of Platelet-Rich Plasma in Combination Wound Therapy With a Gelatin Sheet and Freeze-Dried Platelet-Rich Plasma: A Case Report, Eplasty. 16 (2016) e22.

[212] Y. Yamada, S. Nakamura, M. Ueda, K. Ito, Papilla regeneration by injectable stem cell therapy with regenerative medicine: long-term clinical prognosis, J. Tissue Eng. Regen. Med. 9 (2015) 305-309.

[213] https://clinicaltrials.gov/ct2/show/NCT03227367, acessed in 20.07.2017.

[214] http://www.collplant.com/products/orthobiologics/vergenixstr/, acessed in 27.07.2017.

[215] M.S. Shive, W.D. Stanish, R. McCormack, F. Forriol, N. Mohtadi, S. Pelet, J. Desnoyers, S. Méthot, K. Vehik, A. Restrepo, BST-CarGel ${ }^{\circledR}$ treatment maintains cartilage repair superiority over microfracture at 5 years in a multicenter randomized controlled trial, Cartilage. 6 (2015) 62-72.

[216] J.C. Riboh, B.M. Saltzman, A.B. Yanke, L. Fortier, B.J. Cole, Effect of leukocyte concentration on the efficacy of platelet-rich plasma in the treatment of knee osteoarthritis, Am. J. Sports Med. 44 (2016) 792-800. 
[217] L.P. Lai, T.P. Stitik, P.M. Foye, J.S. Georgy, V. Patibanda, B. Chen, Use of plateletrich plasma in intra-articular knee injections for osteoarthritis: a systematic review, PM\&R. 7 (2015) 637-648.

[218] G. Filardo, B. Di Matteo, E. Kon, G. Merli, M. Marcacci, Platelet-rich plasma in tendon-related disorders: results and indications, Knee Surg. Sports Traumatol. Arthrosc. (2016) 1-16.

[219] A.L. Nelson, E. Dhimolea, J.M. Reichert, Development trends for human monoclonal antibody therapeutics, Nat. Rev. Drug Discov. 9 (2010) 767-774.

[220] M.I. Neves, M.E. Wechsler, M.E. Gomes, R.L. Reis, P.L. Granja, N.A. Peppas, Molecularly imprinted intelligent scaffolds for tissue engineering applications, Tissue Eng. Part B Rev. 23 (2017) 27-43.

[221] G. Vlatakis, L.I. Andersson, R. Muller, K. Mosbach, Drug assay using antibody mimics made by molecular imprinting, Nature. 361 (1993) 645-647.

[222] B. Han, Z. Yang, J.Y. Fang, K. Kuwahara, M. Nimni, J. Thanasukarn, C. Tayag, The Effects of Heparin Binding Proteins in Platelet Releasate on Bone Formation, Tissue Eng. Part A. 20 (2014) 1263-1270.

[223] J. Malda, J. Boere, C.H. Van De Lest, P.R. Van Weeren, M.H. Wauben, Extracellular vesicles--new tool for joint repair and regeneration, Nat. Rev. Rheumatol. . $12(2016) 243$.

[224] G.D. Prestwich, S. Bhatia, C.K. Breuer, S.L. Dahl, C. Mason, R. McFarland, D.J. McQuillan, J. Sackner-Bernstein, J. Schox, W.E. Tente, What is the greatest regulatory challenge in the translation of biomaterials to the clinic?, Sci. Transl. Med. 4 (2012) $160 \mathrm{~cm} 114$. 